\begin{tabular}{|c|l|}
\hline Title & Cross section measurement of al pha particle induced nuclear reactions on natural cadmium up to 52 MeV \\
\hline Author(s) & Ditrói, F.; T akács, S.; Haba, H.; Komori, Y.; A ikawa, Masay uki \\
\hline Citation & $\begin{array}{l}\text { A pplied radiation and isotopes, 118, 266-276 } \\
\text { https://doi.org/10.1016/.apradiso.2016.09.031 }\end{array}$ \\
\hline Issue Date & 2016-12 \\
\hline Doc URL & http://hdl.handle.net/2115/2066 \\
\hline Rights & $\begin{array}{l}\text { O2016. This manuscript version is made available under the CC-BY-NC-ND 4.0 license } \\
\text { http://creativecommons.org/icenses/by-nc-nd/4.0/ }\end{array}$ \\
\hline Rights(URL) & http://creativecommons.org/icenses/by-nc-nd/4.0/ \\
\hline Type & Paper1.pdf \\
\hline article (author version)
\end{tabular}

Instructions for use 


\title{
Cross section measurement of alpha particle induced nuclear reactions on natural cadmium up to $52 \mathrm{MeV}$
}

\author{
F. Ditrói ${ }^{\mathrm{a}, *}$, S. Takács ${ }^{\mathrm{a}}$, H. Haba ${ }^{\mathrm{b}}$, Y. Komori ${ }^{\mathrm{b}}$, M. Aikawa ${ }^{\mathrm{c}}$ \\ ${ }^{a}$ Institute for Nuclear Research, Hungarian Academy of Sciences (ATOMKI), Debrecen, Hungary \\ ${ }^{b}$ Nishina Center for Accelerator-Based Science, RIKEN, Wako, Japan \\ ${ }^{c}$ Faculty of Science, Hokkaido University, Sapporo, Japan
}

\begin{abstract}
Cross sections of alpha particle induced nuclear reactions have been measured on thin natural cadmium targets foils in the energy range from 11 to $51.2 \mathrm{MeV}$. This work was a part of our systematic study on excitation functions of light ion induced nuclear reactions on different target materials. Regarding the cross sections, the alpha induced reactions are not deeply enough investigated. Some of the produced isotopes are of medical interest, others have application in research and industry. The radioisotope ${ }^{117 m} \mathrm{Sn}$ is a very important theranostic (therapeutic + diagnostic) radioisotope, so special care was taken to the results for that isotope. The well-established stacked foil technique followed by gamma-spectrometry with HPGe gamma spectrometers were used. The target and monitor foils in the stack were commercial high purity metal foils. From the irradiated targets ${ }^{117 m} \mathrm{Sn},{ }^{113} \mathrm{Sn},{ }^{110} \mathrm{Sn},{ }^{117 m, g} \mathrm{In},{ }^{116 m} \mathrm{In},{ }^{115 m} \mathrm{In},{ }^{114 m} \mathrm{In}$, ${ }^{113 m} \mathrm{In},{ }^{111} \mathrm{In},{ }^{110 m, g} \mathrm{In},{ }^{109 m} \mathrm{In},{ }^{108 m} \mathrm{In},{ }^{115 g} \mathrm{Cd}$ and ${ }^{111 m} \mathrm{Cd}$ were identified and their excitation functions were derived. The results were compared with the data of the previous measurements from the literature and with the results of the theoretical nuclear reaction model code calculations TALYS 1.8 (TENDL-2015) and EMPIRE 3.2 (Malta). From the cross section curves thick target yields were calculated and compared with the available literature data.
\end{abstract}

Keywords: natural cadmium target, Ti monitor, alpha particle irradiation, $\mathrm{Sn}, \mathrm{In}$ and Cd radioisotopes, integral yield, theoretical nuclear reaction model codes

\section{Introduction}

Cadmium is a metal used in industry as an alloying element in different construction materials and as plating element for corrosion resistance. Its natural occurrence consists of 8 stable isotopes with the composition of ${ }^{106} \mathrm{Cd}$ : $0.0125,{ }^{108} \mathrm{Cd}$ : $0.0089,{ }^{110} \mathrm{Cd}$ : 0.1251 , ${ }^{111} \mathrm{Cd}: 0.1281,{ }^{112} \mathrm{Cd}: 0.2413,{ }^{113} \mathrm{Cd}: 0.1222,{ }^{114} \mathrm{Cd}$ : 0.2872 , and ${ }^{116} \mathrm{Cd}: 0.0747$. Its toxicity limits the biological applicability, but some compounds might be important also in biology. It is also used to control neutron flux in nuclear fission reactors (InternationalCadmium-Association, 2016). Our interest for cadmium was induced by its use as target material in order to produce some medically and industrially important radioisotopes. Among these radioisotopes the most important is the so called theranostic (therapeutic + diagnostic) radioisotope ${ }^{117 m} \mathrm{Sn}$ (Baum, 2014; Ditrói et al., 2016; Stevenson et al., 2015), but it has also nononcological use in the medicine (Simon et al., 2013;

${ }^{*}$ Corresponding author: ditroi@atomki.hu
Stevenson et al., 2015). The diagnostic applicability is based on its good detectable gamma-lines and reasonable half-life $\left(\mathrm{T}_{1 / 2}=13.76 \mathrm{~d}\right.$ ) (Knapp et al., 1983; NuDat, 2014). Besides the reactor production (Mausner et al., 1985), which results in low specific activity final product (Srivastava et al., 2004) ${ }^{117 m} \mathrm{Sn}$ can also be produced by high energy protons on antimony target resulting in NCA (non-carrier-added) end product (Ermolaev et al., 2009). The most promising route of the production is the high energy alpha particle induced reaction on natural cadmium or rather enriched ${ }^{116} \mathrm{Cd}$ target material (Stevenson et al., 2015). ${ }^{111 g}$ In is used for diagnostic medicine for labeling antibodies or blood cell components, as $\gamma$-emitters for SPECT studies (Qaim, 2012). This radioisotope is mainly produced on enriched ${ }^{112} \mathrm{Cd}$ by using proton irradiation in the energy range up to 25 $\mathrm{MeV}$. The use of ${ }^{111} \mathrm{In}$ for Auger-electron therapy is also considered recently (Qaim, 2012). The series of other radioisotopes investigated in our present experiment are usually emerged by medical radioisotope production as by-product or contamination and that is why the knowl-

February 8, 2017 
edge of their excitation function and yield is almost as important as that of the designed radioisotopes. From the industrial point of view, as a radioactive tracer, those product radioisotopes could be interesting, which have suitable long half-life, proper gamma-energy with intense radiation and good production parameters (high yield within the energy range of the available accelerator). Taking into account the above conditions, ${ }^{113} \mathrm{Sn}$ and ${ }^{111}$ In can be good candidates. A measurement on a natural target is important, because any enriched target material contains all natural components in a different ratio and radioisotopes produced from them are contaminants in the final products. For estimation of the contaminating amount of different radioisotopes it is necessary to use the experimental results on natural target composition. Earlier studies of alpha particle induced reactions mainly targeted the production of medically important radioisotopes, such as ${ }^{117 m} \mathrm{Sn}$ (Andreyev et al., 1999; Ditrói et al., 2016; Fukushima et al., 1963; Knapp et al., 1983; Qaim and Dohler, 1984) but there are also studies giving experimental data for all detectable radio-products (Adam-Rebeles et al., 2008; Hermanne et al., 2010; Qaim, 2015; Qaim and Dohler, 1984).

\section{Experimental}

Our Cd targets were high-purity commercial (Goodfellow) foils with a measured thickness of $15.6 \mu \mathrm{m}$. The composition of the stack is shown in Fig. 1. The stack was assembled from 11 identical groups of Cd-Cd-Ti target foils, where the $10.9 \mu \mathrm{m}$ Ti foils are served both as monitor and as catcher foils for the radioactive recoil products from the preceding $\mathrm{Cd}$ foil. The double $\mathrm{Cd}$ foil configuration was also used to be able to correct for the recoil products. The irradiation was performed at the beam line of the AVF cyclotron of RIKEN RI Beam Factory by using an $\mathrm{E}_{\alpha}=51.2 \mathrm{MeV}$ alpha beam. The beam energy was determined by Time of Flight (TOF) method (Watanabe, 2015; Watanabe et al., 2014). The irradiation time was slightly more than one hour and the beam current did not exceed $50 \mathrm{nA}$ and it was kept constant within $5 \%$ during the whole irradiation. The collected charge was recorded in every minute in order to determine the total collected charge as well as for confirmation of the beam stability. After a short cooling time the stack was disassembled and the gamma-spectra of the target foils were measured by using ORTEC HPGe gamma spectrometers with the corresponding electronics and evaluation software. The target foils were measured several times to catch both the short-lived (short cooling time and short measuring time) and the long-lived (longer cooling time and longer measuring time) radioactive products. After evaluation also a recoil correction was made by using the data of the products caught in the Ti foils. The evaluated results for the monitor foils are shown in Fig. 2 based on the ${ }^{n a t} \mathrm{Ti}(\alpha, \mathrm{x})^{51} \mathrm{Cr}$ monitor reaction by comparing our evaluated cross section values with the upgraded recommended curve from the IAEA monitor reaction database (Tárkányi et al., 2001). Figure 2 shows a good agreement between our monitor data and the recommended excitation function. The cross sections of the different nuclear reactions were assessed by using the well-known activation formula by using the peak areas, irradiation, cooling and measuring times and the nuclear data of the reactions and isotopes in Table 1 (NuDat, 2014). The uncertainties of the calculated data were determined by taking square root from the sum in quadrature of all individual contributions (InternationalBureau-of-Weights-and-Measures, 1993): number of incident particles $(5 \%)$, target thickness $(2 \%)$, detector efficiency $(5 \%)$, nuclear data (3\%), peak areas (1-20\%). The average uncertainty in the assessed cross sections was than $8-20 \%$.

\section{Nuclear reaction model code calculations}

Our new experimental data were also compared with the calculated results of two nuclear reaction model codes. TALYS (Koning et al., 2007), recent version 1.8 is available on-line (Koning et al., 2015a) and its latest calculated results are tabulated in the in the TENDL2015 on-line library (Koning and Rochman, 2013; Koning et al., 2015b). The on-line tabulated version contains adjusted results of the TALYS code. Calculations were also performed with the newest version of the EMPIRE code (Herman et al., 2007), the EMPIRE 3.2 (Malta) (Herman et al., 2012), which uses the latest reference input parameters library RIPL-3 (Capote et al., 2009). The codes were launched with the default input parameters and all possible reaction channels were considered, including emission of complex particles at our bombarding energies. The level density fits were adjusted after the first run of the EMPIRE 3.2 code. Comparison of the codes output with our new experimental results could help the developers to improve the models behind these calculations.

\section{Excitation functions}

The experimental excitation functions obtained in this experiment are presented graphically in Figs. 319 and numerically in Tables 2 and 3. The results are 


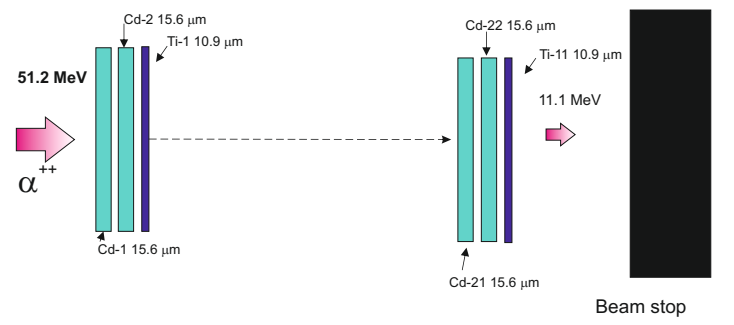

Figure 1: Schematic set-up of the irradiated stack

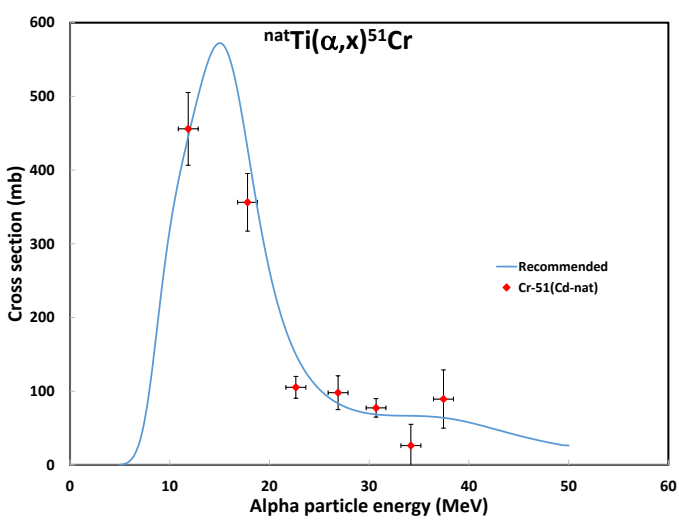

Figure 2: Comparison the results on our monitor foils with the recommended cross section of the ${ }^{n a t} \operatorname{Ti}(\alpha, \mathrm{x}){ }^{51} \mathrm{Cr}$ reaction compared with the previous measurements found in the literature and also with the results of the theoretical nuclear model code calculations.

\section{Comparison with nuclear model calculations}

The experimental excitation functions obtained in this experiment are presented graphically in Figs. 319 and numerically in Tables 2 and 3. The results are compared with the previous measurements found in the literature and also with the results of the theoretical nuclear model code calculations.

\subsection{The ${ }^{\text {nat }} C d(\alpha, x)^{117 m}$ Sn reactions}

The $\mathrm{Sn}$ radioisotopes are produced directly in $(\alpha, \mathrm{xn})$ reactions by emission of neutrons. The ${ }^{117 m} \mathrm{Sn}$ radioisotope can only be produced directly from the two highest mass number cadmium isotopes through the ${ }^{114} \mathrm{Cd}(\alpha, 3 \mathrm{n})$ and ${ }^{116} \mathrm{Cd}(\alpha, \mathrm{n})$ reactions. It is also formed from the decay of the $\mathrm{A}=117$ mass number isobar chain. In order to let the $A=117$ parents decay, our results were determined from a late measurement series, in such a way our results are cumulative for the ${ }^{117 m} \mathrm{Sn}$ radioisotope (Fig. 3). Both TENDL-2015 and EMPIRE 3.2 follow the trend of our new experimental data. Below $25 \mathrm{MeV}$ the TENDL-2015 approximation is better but above $40 \mathrm{MeV}$ EMPIRE 3.2 gives closer approach. Between 25 and $40 \mathrm{MeV}$ both theoretical codes underestimate slightly our experimental results. The new results are in good agreement with the recent data of (Duchemin et al., 2016) above $32 \mathrm{MeV}$ and slightly higher below $32 \mathrm{MeV}$. The data of (Khandaker et al., 2014) are slightly higher than ours below $35 \mathrm{MeV}$ and show acceptable agreement above this energy, except one salient value at $39.5 \mathrm{MeV}$. The previous experimental works of (Qaim and Dohler, 1984) and (Hermanne et al., 2010) report completely different results far away both from our data and from each other. They do not show the trend reproduced by the theoretical model codes.

\subsection{The ${ }^{\text {nat }} C d(\alpha, x)^{113}$ Sn reactions}

The ${ }^{113} \mathrm{Sn}$ has two isomeric states, both can be produced directly from the $\mathrm{A}=110-114$ stable cadmium isotopes by $(\alpha, \mathrm{xn})$ reactions. Its $\mathrm{T}_{1 / 2}=21.4 \mathrm{~min}$ excited state decays partly to the longer-lived ground state, so the spectra measured after the complete decay of the isomeric state were used in our calculations. Our new results are shown in Fig. 4 in comparison with the previous experimental results from the literature and 


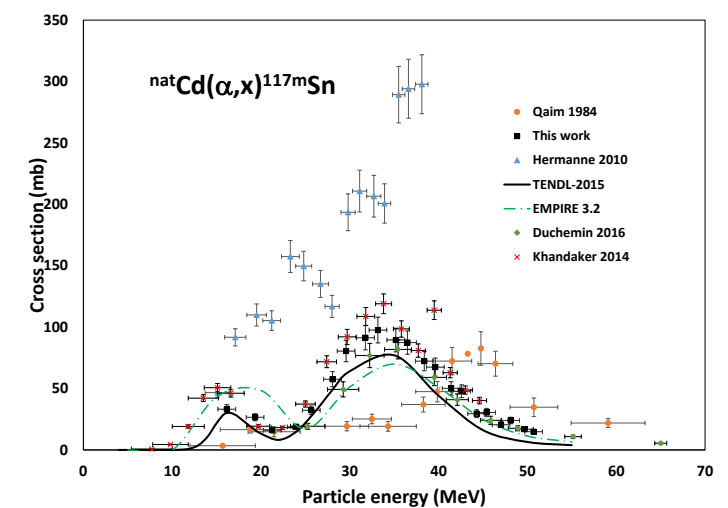

Figure 3: Excitation function of the ${ }^{n a t} \mathrm{Cd}(\alpha, \mathrm{x})^{117 m} \mathrm{Sn}$ nuclear reactions in comparison with the previous experiments from the literature and with the results of the nuclear reaction model code calculations

with the theoretical nuclear reaction model code calculations. The new data are in good agreement with the TENDL-2015 prediction taking into account the cumulative cross section. TENDL-2015 could even reproduce the local minimum in the $15-25 \mathrm{MeV}$ energy region. EMPIRE 3.2 gives much lower results and very different shape. The previous experimental data agree neither with the new data nor with each other or with the theoretical predictions. The recent data set of (Duchemin et al., 2016) supports our data above 45 $\mathrm{MeV}$ and below $32 \mathrm{MeV}$, but it cannot reproduce the maximum of the excitation function. The data of (Khandaker et al., 2014) are also lower than our values except for one data point at $16 \mathrm{MeV}$.

\subsection{The ${ }^{\text {nat }} C d(\alpha, x)^{110}$ Sn reactions}

The radioisotope ${ }^{110} \mathrm{Sn}$ has a relatively short half-life $\left(\mathrm{T}_{1 / 2}=4.11 \mathrm{~h}\right)$, which requires quick measurements with short cooling times. Only direct production is possible from the stable cadmium isotopes in the $\mathrm{A}=$ 108-111 mass region in the used energy range. Our results are in excellent agreement with the previous data of (Hermanne et al., 2010) and (Khandaker et al., 2014) (Fig. 5). The data of (Duchemin et al., 2016) are slightly lower, especially above $40 \mathrm{MeV}$. The TENDL-2015 prediction is lower below $40 \mathrm{MeV}$ but above that energy becomes higher than our values. EMPIRE 3.2 gives almost the same estimation as TENDL-2015 up to 40 $\mathrm{MeV}$, but strongly declines above this energy.

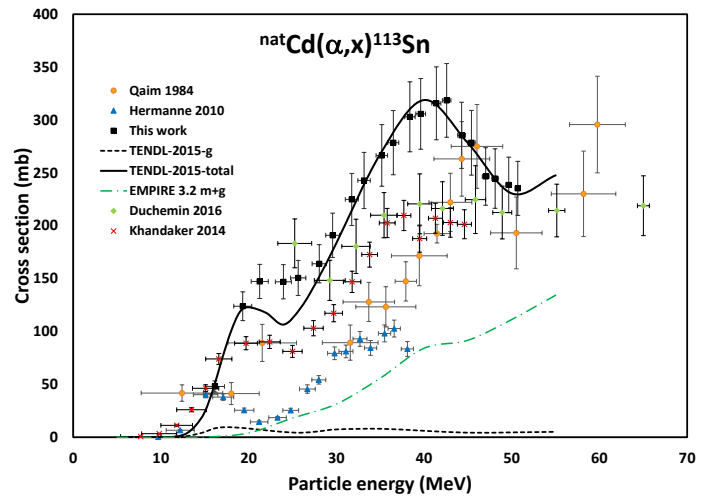

Figure 4: Excitation function of the ${ }^{n a t} \mathrm{Cd}(\alpha, \mathrm{x})^{113} \mathrm{Sn}$ nuclear reactions in comparison with the previous experiments from the literature and with the results of the nuclear reaction model code calculations

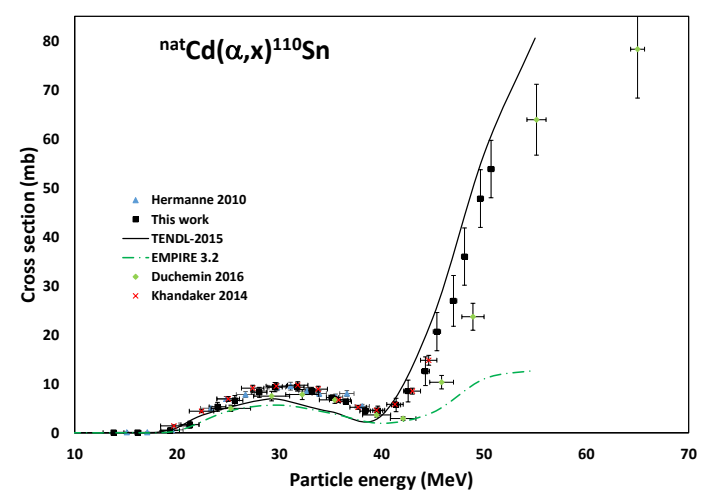

Figure 5: Excitation function of the ${ }^{n a t} \mathrm{Cd}(\alpha, \mathrm{x})^{110} \mathrm{Sn}$ nuclear reactions in comparison with the previous experiments from the literature and with the results of the nuclear reaction model code calculations 


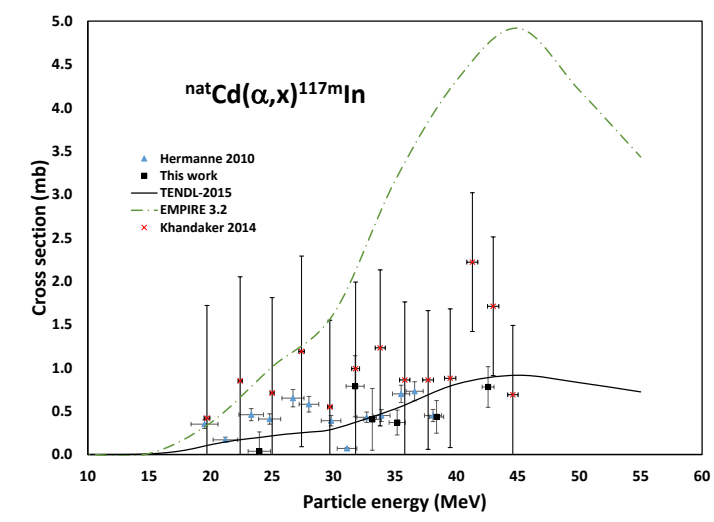

Figure 6: Excitation function of the ${ }^{n a t} \mathrm{Cd}(\alpha, \mathrm{x})^{117 m} \mathrm{In}$ nuclear reactions in comparison with the previous experiments from the literature and with the results of the nuclear reaction model code calculations

\subsection{The ${ }^{\text {nat }} C d(\alpha, x)^{117 m}$ In reactions}

The direct production of indium isotopes in alpha bombardment of cadmium targets requires also the emission of a proton in an ( $\alpha$,pxn) reaction. ${ }^{117 m}$ In can be produced on ${ }^{114} \mathrm{Cd}$ and ${ }^{116} \mathrm{Cd}$ only. The activity of ${ }^{117 m}$ In can be independently measured through its 315.3 $\mathrm{keV}$ gamma-line. This isomeric level can also be fed from the parent ${ }^{117} \mathrm{Cd}$ radioisotope, which was not detected in our spectra. The new data are presented in Fig. 6 together with the previous experimental results and with the results of TALYS-2015 and EMPIRE 3.2 model code calculations. Because of the low counting statistics both our and the previous data of (Hermanne et al., 2010) are slightly scattered, but show an acceptable agreement and also agree with the TENDL-2015 prediction, while EMPIRE 3.2 gives large overestimation. It is difficult to judge the agreement with the recent data of (Khandaker et al., 2014), because they report extraordinary large uncertainties.

\subsection{The ${ }^{\text {nat }} C d(\alpha, x)^{117 g}$ In reactions}

The ground state of ${ }^{117} \mathrm{In}$ is produced in the same reactions as its excited state (see above), and the ground state is also fed by decay of its excited state. A short cooling time was necessary to decrease the decay corrections from the higher isomeric state. Our new data are shown in Fig. 7 together with the previous experimental results and the results of the model code calculations. Our new data are in good agreement with the previous results of (Hermanne et al., 2010) and with the results of (Khandaker et al., 2014). EMPIRE 3.2 predicts well the experimental values up to $30 \mathrm{MeV}$. The

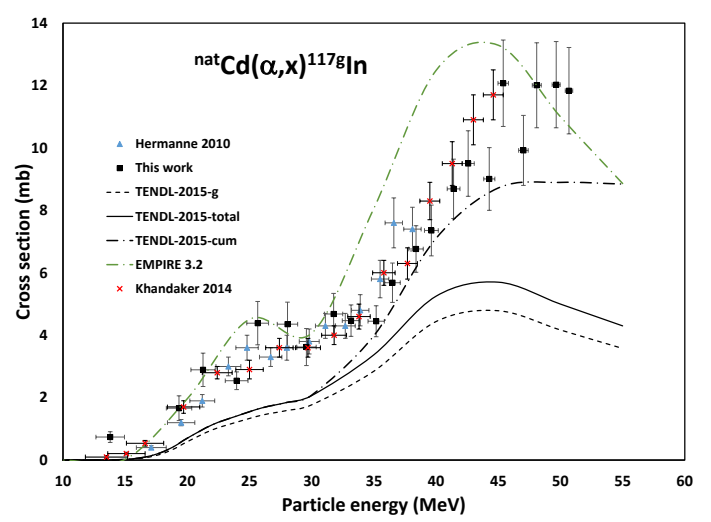

Figure 7: Excitation function of the ${ }^{n a t} \mathrm{Cd}(\alpha, \mathrm{x})^{117 g}$ In nuclear reactions in comparison with the previous experiments from the literature and with the results of the nuclear reaction model code calculations

TENDL-2015 approximation underestimates the experimental values even if cumulative results are considered.

\subsection{The ${ }^{\text {nat }} C d(\alpha, x)^{116 m 2}$ In reactions}

The radioisotope ${ }^{116}$ In can only be produced by direct reactions. The ${ }^{116} \mathrm{In}$ has a very short-lived $\left(\mathrm{T}_{1 / 2}=2.18\right.$ $\mathrm{s})$ isomeric state, a longer-lived $\left(\mathrm{T}_{1 / 2}=54.29 \mathrm{~min}\right)$ isomeric state and a very short-lived $\left(\mathrm{T}_{1 / 2}=14.1 \mathrm{~s}\right)$ ground state. The ground state has a small EC branch to the stable ${ }^{116} \mathrm{Cd}$, and the $2.18 \mathrm{~s} \mathrm{~m} 1$ isomeric state decays to the $54.29 \mathrm{~min} \mathrm{~m} 2$ isomeric state, thus the result will be cumulative $(\mathrm{m} 1+\mathrm{m} 2)$. Because of the short half-lives only the $54.29 \mathrm{~min}{ }^{116 m 2}$ In was detectable for us from the first series of the measurements with short cooling times. The results are presented in Fig. 8 together with the results of the previous experiments from the literature and the results of the theoretical model code calculations. The new data are in excellent agreement with the previous results of (Hermanne et al., 2010; Khandaker et al., 2014). The EMPIRE 3.2 overestimates while TENDL2015 underestimates the experimental data significantly.

\subsection{The ${ }^{\text {nat }} C d(\alpha, x)^{115 m}$ In reactions}

The radioisotope ${ }^{115} \mathrm{In}$ is produced directly on the stable cadmium isotopes with $\mathrm{A}=112-116$ in the applied energy range. Decay of the ${ }^{115} \mathrm{Cd}$ parent isotope also contributes to its production. The ${ }^{115} \mathrm{Cd}$ decays by $97 \%$ to the almost stable ground state $\left(\mathrm{T}_{1 / 2}=4.141014 \mathrm{a}\right)$. Because the half-life of the parent isotope is an order of magnitude longer than the daughter of interest, a quick measurement by short cooling time makes the mothers 


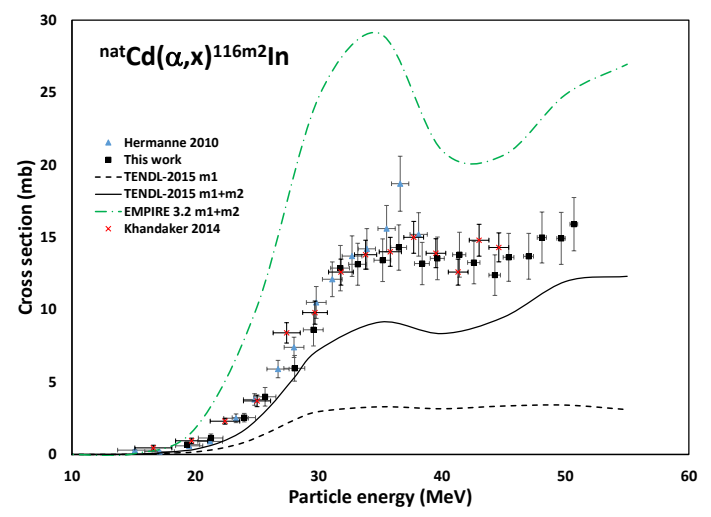

Figure 8: Excitation function of the ${ }^{n a t} \operatorname{Cd}(\alpha, \mathrm{x})^{116 m}$ In nuclear reactions in comparison with the previous experiments from the literature and with the results of the nuclear reaction model code calculations

contribution negligible. The results of the present experiment are shown in Fig. 9 together with the previous experimental values and the results of the model code calculations. Our new results are in excellent agreement with the previous data of (Hermanne et al., 2010; Khandaker et al., 2014). The agreement with the TENDL2015 curve is also acceptable, but the EMPIRE 3.2 gives much higher values.

\subsection{The ${ }^{\text {nat }} C d(\alpha, x)^{114 m}$ In reactions}

The ${ }^{114}$ In can be produced from stable cadmium isotopes with $\mathrm{A}=111-116$ in direct nuclear reactions with the used bombarding beam energy. There is no parent isotope to feed its population. The relatively long half-life of ${ }^{114 m}$ In $\left(\mathrm{T}_{1 / 2}=49.51 \mathrm{~d}\right)$ makes a convenient measurement possible. The results of the present experiment are shown in Fig. 10 together with the previous experimental values and the results of the model code calculations. Our results are in good agreement with the previous experimental data of (Hermanne et al., 2010). The recent results of (Duchemin et al., 2016) agree with us up to $40 \mathrm{MeV}$ and become smaller at the higher energies. Both our and their dataset are a bit scattered above $40 \mathrm{MeV}$. The recent data of (Khandaker et al., 2014) are somewhat higher than all the others below $32 \mathrm{MeV}$. In general, the TENDL-2015 calculation underestimates, while the curve of the EMPIRE 3.2 calculation overestimates the experimental data.

\subsection{The ${ }^{\text {nat }} \mathrm{Cd}(\alpha, x)^{113 m}$ In reactions}

The ${ }^{113 m}$ In radioisotope can be produced directly from $\mathrm{A}=110-114$ stable cadmium isotopes in our en-

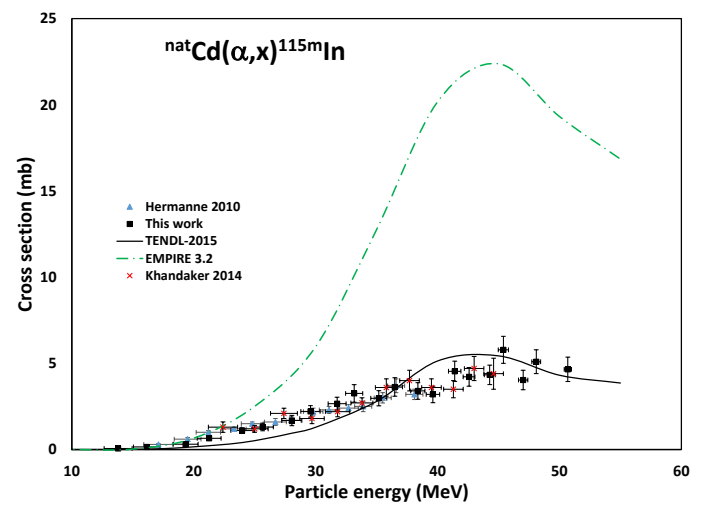

Figure 9: Excitation function of the ${ }^{n a t} \operatorname{Cd}(\alpha, \mathrm{x})^{115 m} \mathrm{In}$ nuclear reactions in comparison with the previous experiments from the literature and with the results of the nuclear reaction model code calculations

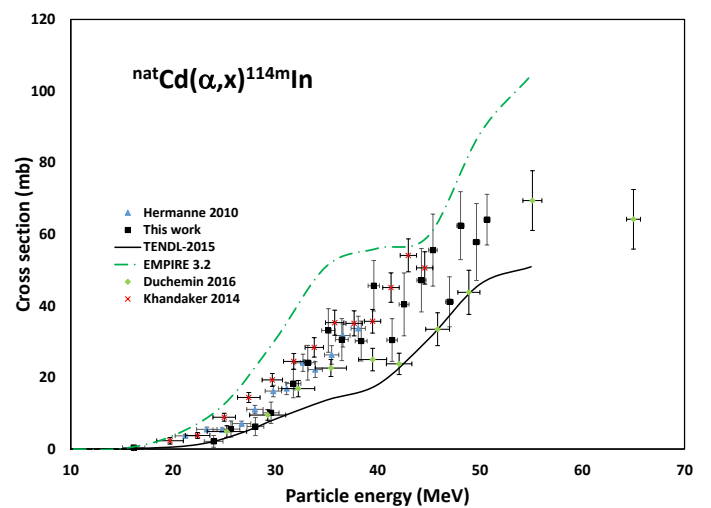

Figure 10: Excitation function of the ${ }^{n a t} \operatorname{Cd}(\alpha, x)^{114 m}$ In nuclear reactions in comparison with the previous experiments from the literature and with the results of the nuclear reaction model code calculations 


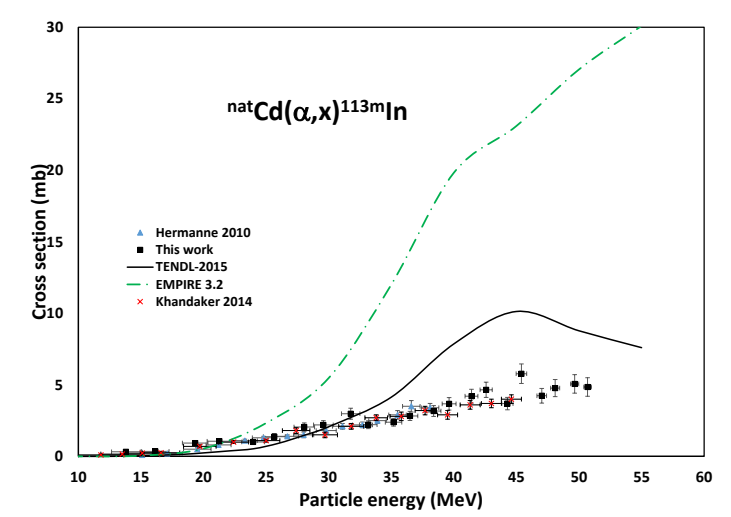

Figure 11: Excitation function of the ${ }^{n a t} \operatorname{Cd}(\alpha, \mathrm{x})^{113 m}$ In nuclear reactions in comparison with the previous experiments from the literature and with the results of the nuclear reaction model code calculations

ergy range. The parent isotope ${ }^{113 g} \mathrm{Sn}$ feeds its production, but it was easy to calculate the necessary corrections because their half-lives are very different and the cross section of the ${ }^{113} \mathrm{Sn}$ is also measured. Our new results are shown in Fig. 11 together with the previous experimental values and the results of the model code calculations. The new data are in excellent agreement with the previous values of (Hermanne et al., 2010; Khandaker et al., 2014) in the whole overlapping region. The TENDL-2015 calculation underestimates the experimental results below $28 \mathrm{MeV}$, and overestimates above $32 \mathrm{MeV}$. The EMPIRE 3.2 calculation provides much higher estimation.

\subsection{The ${ }^{\text {nat }} C d(\alpha, x)^{111}$ In reactions}

The radioisotope ${ }^{111} \mathrm{In}$ is produced directly from the $\mathrm{A}=108-113$ stable cadmium isotopes in our energy range. The ${ }^{111 m} \mathrm{Cd}$ decays by $100 \%$ IT to the ground state therefore does not contribute to the production of ${ }^{111} \mathrm{In}$. The shorter-lived $\left(\mathrm{T}_{1 / 2}=35.3 \mathrm{~min}\right){ }^{111} \mathrm{Sn}$ decays with $\varepsilon=100 \%$ to ${ }^{111} \mathrm{In}$. Spectra measured after the complete decay of the parent radioisotope were used to assess the cumulative cross section. The results are shown in Fig. 12 together with the previous experimental values and the results of the model code calculations. Our new results are in excellent agreement with the previous data of (Hermanne et al., 2010) and (Khandaker et al., 2014), and are somewhat higher than the recent data of (Duchemin et al., 2016). The TENDL-2015 cumulative predictions are in good agreement with the experimental data up to $35 \mathrm{MeV}$, but they are lower above $36 \mathrm{MeV}$. Above $36 \mathrm{MeV}$, the EMPIRE 3.2 declines considerably.

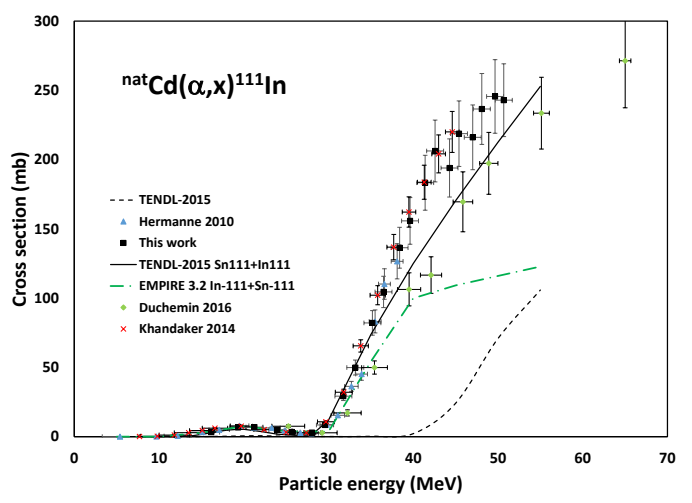

Figure 12: Excitation function of the ${ }^{\text {nat }} \operatorname{Cd}(\alpha, \mathrm{x})^{111}$ In nuclear reactions in comparison with the previous experiments from the literature and with the results of the nuclear reaction model code calculations

\subsection{The ${ }^{\text {nat }} C d(\alpha, x)^{110 m}$ In reactions}

The ${ }^{110 m}$ In is produced by direct nuclear reactions from the $\mathrm{A}=108-112$ stable cadmium isotopes in the used energy range. Its production is also fed partly by decay of ${ }^{110} \mathrm{Sn} .{ }^{110} \mathrm{Sn}$ has longer half-life than ${ }^{110 m} \mathrm{In}$, so its contribution is unavoidable. The cross section of the ${ }^{110} \mathrm{Sn}$ production could be measured independently, and in such a way its contribution could be subtracted from the measured activities. The corrected results are shown in Fig. 13 together with the previous experimental values and the results of the model code calculations. Our new results are slightly lower than the previous results of (Hermanne et al., 2010) and in good agreement with the TENDL-2015 predictions. EMPIRE 3.2 also gives acceptable estimation. The data of (Khandaker et al., 2014) gives significantly larger values, especially in the energy range below $40 \mathrm{MeV}$.

\subsection{The ${ }^{\text {nat }} C d(\alpha, x)^{110 g}$ In reactions}

The radioisotope ${ }^{110 g}$ In can be produced directly on ${ }^{108-112} \mathrm{Cd}$ at the used bombarding energy. The ${ }^{110 m} \mathrm{In}$ isomeric level decays directly to ${ }^{110} \mathrm{Cd}$, and there is no contribution from the ${ }^{110} \mathrm{Sn}$ decay to ${ }^{110 g} \mathrm{In}$ radioisotope. The results are independent and shown in Fig. 14 together with the previous experimental values and the results of the model code calculations. Our new results are in excellent agreement with the previous data of (Hermanne et al., 2010), (Khandaker et al., 2014) and (Duchemin et al., 2016). Both theoretical nuclear reaction model codes agree well up to $42 \mathrm{MeV}$. Above this energy the TENDL-2015 gives higher, while EMPIRE 3.2 gives lower values. 


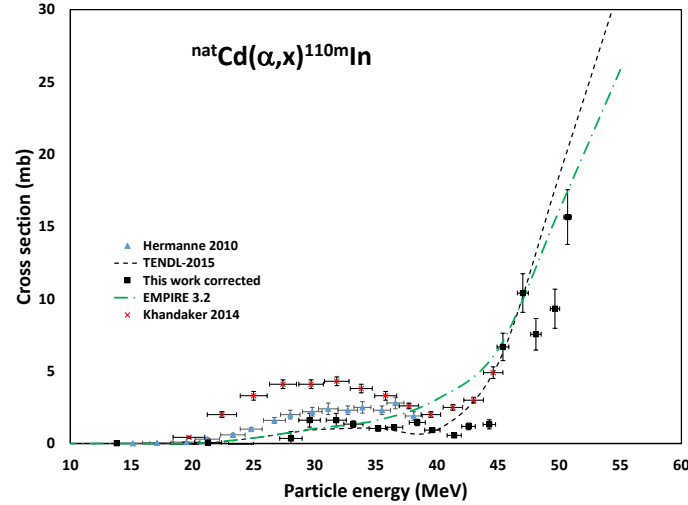

Figure 13: Excitation function of the ${ }^{n a t} \operatorname{Cd}(\alpha, \mathrm{x})^{110 m}$ In nuclear reactions in comparison with the previous experiments from the literature and with the results of the nuclear reaction model code calculations

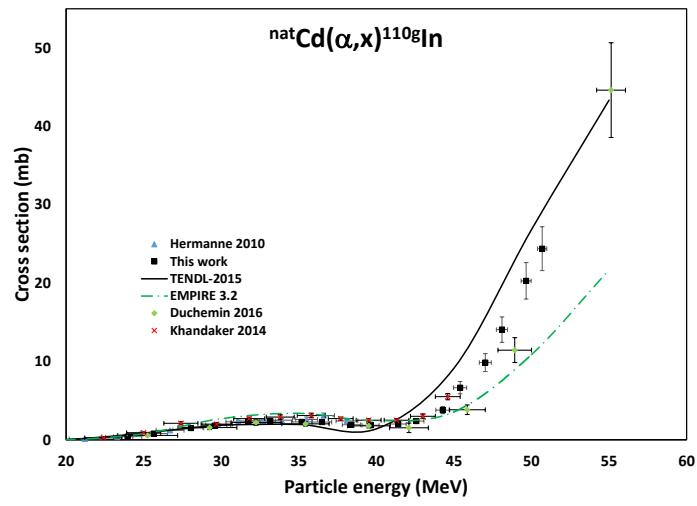

Figure 14: Excitation function of the ${ }^{\text {nat }} \operatorname{Cd}(\alpha, \mathrm{x})^{110 g}$ In nuclear reactions in comparison with the previous experiments from the literature and with the results of the nuclear reaction model code calculations

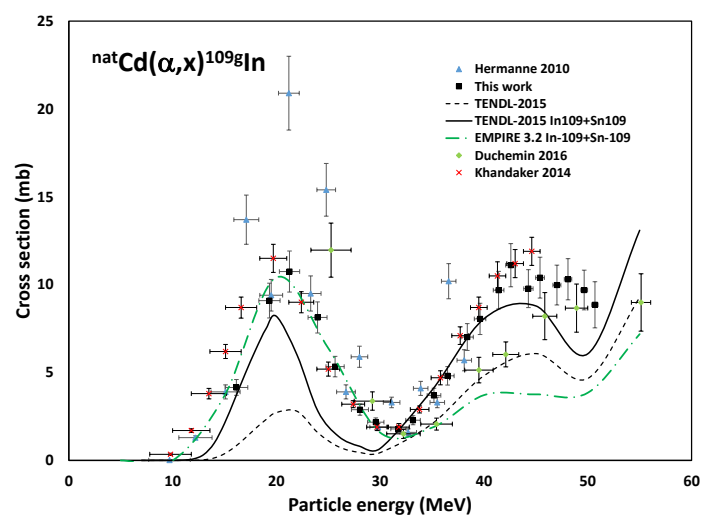

Figure 15: Excitation function of the ${ }^{\text {nat }} \mathrm{Cd}(\alpha, \mathrm{x})^{109 g}$ In nuclear reactions in comparison with the previous experiments from the literature and with the results of the nuclear reaction model code calculations

\subsection{The ${ }^{\text {nat }} C d(\alpha, x)^{109 g}$ In reactions}

The radioisotope ${ }^{109 g}$ In can be produced directly on the $\mathrm{A}=106-111$ stable cadmium isotopes in the used energy range. It has two short-lived metastable states decaying completely onto the ground state. Decay of the parent ${ }^{109} \mathrm{Sn}$ contributes to its production. The ${ }^{109} \mathrm{Sn}$ parent isotope is also shorter lived than ${ }^{109 g}$ In in question. Cumulative production cross sections were determined from the second series of spectra taken after proper cooling time. Our new results are shown in Fig. 15 together with the previous experimental values and the results of the model code calculations. The new results are in good agreement with the previous data of (Hermanne et al., 2010), except our results are much lower around the local maximum of $20 \mathrm{MeV}$. The recent data of (Khandaker et al., 2014) are in excellent agreement with our new results and also support our data around the lower energy maximum but seem to have some energy shift at the lower energy points. The recent results of (Duchemin et al., 2016) agree with our data around the $30 \mathrm{MeV}$ local minimum only and could not reproduce the upper maximum at 43 MeV. TENDL-2015 gives relatively good approximation above $32 \mathrm{MeV}$, while the agreement with the EMPIRE 3.2 calculation result is good up to $32 \mathrm{MeV}$.

\subsection{The ${ }^{\text {nat }} C d(\alpha, x)^{108 m}$ In reactions}

The ${ }^{108 m}$ In radioisotope is produced directly from the $\mathrm{A}=106-108$ stable cadmium isotopes in the used energy range. The production of this metastable state of ${ }^{108} \mathrm{In}$ is also fed from decay of the ${ }^{108} \mathrm{Sn}$ parent isotope. 


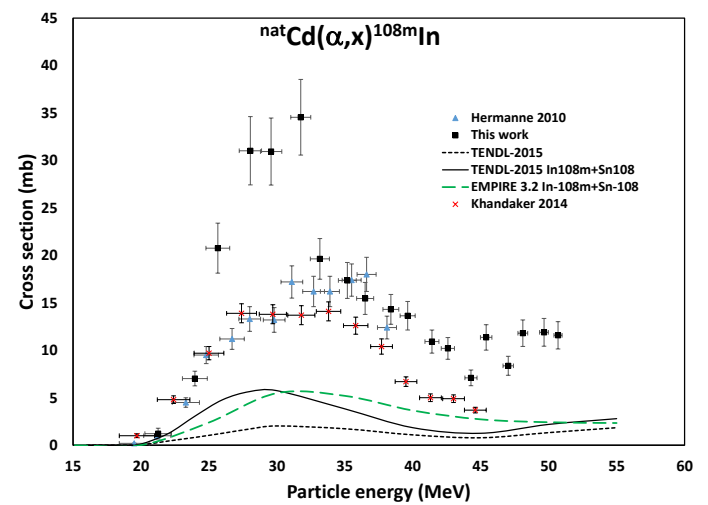

Figure 16: Excitation function of the ${ }^{n a t} \operatorname{Cd}(\alpha, \mathrm{x})^{108 m} \mathrm{In}$ nuclear reactions in comparison with the previous experiments from the literature and with the results of the nuclear reaction model code calculations

Because of the short half-life of the parent $\left(\mathrm{T}_{1 / 2}=10.3\right.$ $\min )$ and the daughter $\left(\mathrm{T}_{1 / 2}=39.6 \mathrm{~min}\right)$ it is difficult to separate them based on their half-life difference. Because no gamma-lines of ${ }^{108} \mathrm{Sn}$ were measured in the present experiment, a correction based on model calculations was possible, which might have caused large uncertainties. The new results are shown in Fig. 16 together with the previous experimental values and the results of the model code calculations. The agreement with the previous data of (Hermanne et al., 2010) is only good around the maximum region, below these energies our data are considerably higher. The recent data of (Khandaker et al., 2014) are lower than our data and those of (Hermanne et al., 2010) above $30 \mathrm{MeV}$. An agreement with our data is only seen below $25 \mathrm{MeV}$. The results of the theoretical nuclear model calculations reproduce the trend of the experimental values but give much lower cross sections.

\subsection{The ${ }^{\text {nat }} C d(\alpha, x)^{108 g}$ In reactions}

The meta-stable state ${ }^{108 m}$ In decays only to the levels of ${ }^{108} \mathrm{Cd}$, so ${ }^{108 g} \mathrm{In}$ is produced only by direct reactions and by decay of ${ }^{108} \mathrm{Sn}$. The half-life of ${ }^{108 g} \mathrm{In}$ is also similar to those of ${ }^{108} \mathrm{Sn}$ and ${ }^{108 m} \mathrm{In}$, so for the evaluation of both isomers the same series of measurements can be used. The calculated cross sections are shown in Fig. 17 together with the previous experimental values and the results of the model code calculations. The new results are in good agreement with the previous experimental values of (Hermanne et al., 2010; Khandaker et al., 2014). The EMPIRE 3.2 model code provides similar shape with somewhat higher maximum value.

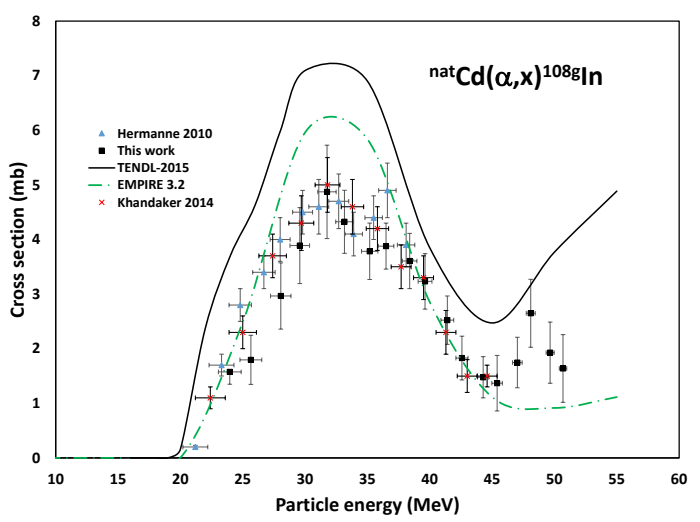

Figure 17: Excitation function of the ${ }^{n a t} \mathrm{Cd}(\alpha, \mathrm{x})^{108 g} \mathrm{In}$ nuclear reactions in comparison with the previous experiments from the literature and with the results of the nuclear reaction model code calculations

The TENDL-2015 gives similar trend as the experimental data but higher values in the whole energy region.

\subsection{The ${ }^{\text {nat }} C d(\alpha, x)^{115 g} C d$ reactions}

The radioisotope ${ }^{115} \mathrm{Cd}$ can be produced directly from the $\mathrm{A}=113-116$ stable cadmium isotopes. Gamma photons from decay of the shorter-lived ground-state were detected in our spectra. This isotope can also be produced by decay of the short-lived ${ }^{115} \mathrm{Ag}$. Cumulative cross sections were measured after the complete decay of the ${ }^{115} \mathrm{Ag}$ parent. The new experimental cross sections are shown in Fig. 18 together with the previous experimental values and the results of the model code calculations. Our new results are in acceptable agreement with the previous data of (Hermanne et al., 2010). The recent results of (Duchemin et al., 2016) and (Khandaker et al., 2014) are somewhat lower and definitely higher above $30 \mathrm{MeV}$, respectively. Both TENDL-2015 and EMPIRE 3.2 agree with the experimental results only up to $32 \mathrm{MeV}$ and give much lower values above this energy.

\subsection{The ${ }^{\text {nat }} C d(\alpha, x)^{111 m} C d$ reactions}

The radioisotope ${ }^{111 m} \mathrm{Cd}$ can be directly produced from the $\mathrm{A}=111-116$ stable cadmium isotopes. The feeding mother isotope is ${ }^{111} \mathrm{Ag}$, which was not detected in our spectra. Contribution from decay of ${ }^{111} \mathrm{In}$ to ${ }^{111 m} \mathrm{Cd}$ is negligible. Our new experimental cross sections are shown in Fig. 19 together with the previous experimental values and the results of the model code calculations. Our new results are in good agreement with 


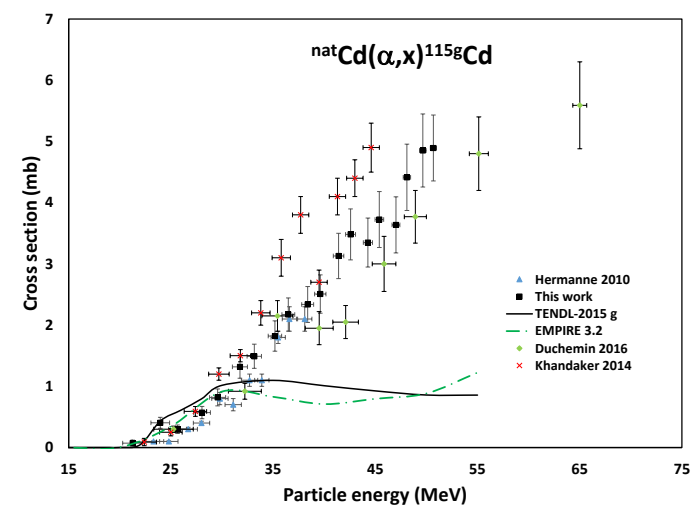

Figure 18: Excitation function of the ${ }^{n a t} \mathrm{Cd}(\alpha, \mathrm{x})^{115 g} \mathrm{Cd}$ nuclear reactions in comparison with the previous experiments from the literature and with the results of the nuclear reaction model code calculations

the previous data of (Hermanne et al., 2010; Khandaker et al., 2014), except for a couple of salient points. The estimations given by both TENDL-2015 and EMPIRE 3.2 are far away from the experimental results both in shape and in value for most of the investigated energy range.

\section{Thick target yields}

The most important radioisotope from this experiment is ${ }^{117 m} \mathrm{Sn}$ and its physical thick target yield is presented in Fig. 20. Our new data are somewhat higher than the previous results of (Fukushima et al., 1963) and lower than the recent data of (Khandaker et al., 2014). There is another experimental result for the thick target yield in the literature from (Maslov et al., 2011). They used a limited target thickness at the $35 \mathrm{MeV}$ bombarding energy. We have calculated a yield from our new cross section data for the same target thickness and composition and got a $0.0115 \mathrm{GBq} / \mathrm{C}$ thick target yield, which is in acceptable agreement with the data published by Maslov et al.: $0.01042 \mathrm{GBq} / \mathrm{C}$. The same figure presents our new yield data for ${ }^{113} \mathrm{Sn}$ together with the previous results of (Dmitriev et al., 1975), which is somewhat lower than our data. For ${ }^{110} \mathrm{Sn}$ the only previous data is from (Khandaker et al., 2014), which is somewhat higher than our new results. The calculated thick target yields of the ${ }^{117 g, 116 m, 115 m, 114 m, 113 m, 111 g}$ In radioisotopes are shown in Fig. 21, together with the available literature data. For ${ }^{113 m}$ In and ${ }^{115 m}$ In our new data are in excellent agreement with the recent data of (Khandaker et al., 2014), but for ${ }^{114 m}$ In our data are

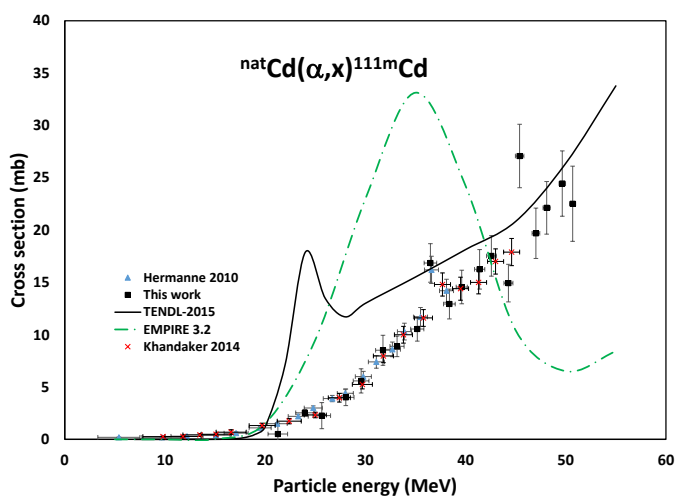

Figure 19: Excitation function of the ${ }^{n a t} \mathrm{Cd}(\alpha, \mathrm{x}){ }^{111} \mathrm{Cd}$ nuclear reactions in comparison with the previous experiments from the literature and with the results of the nuclear reaction model code calculations

lower. No previous data was found for the rest of the radioisotopes presented in Fig. 21. The calculated yields for ${ }^{110 m, g} 109 g, 108 m \mathrm{In},{ }^{115 g, 111 m} \mathrm{Cd}$ are shown in Fig. 22. Our data for ${ }^{110 g}$ In are slightly lower than those of (Khandaker et al., 2014) but in the meta-stable case the data of Khandaker et al. are much higher than ours. These literature data were taken from the IAEA EXFOR database, and if we compare them with the original paper we can recognize that the agreeing data are very different from the graph of the original paper. This confusion might be caused by the fact that in the case of ${ }^{110} \mathrm{In}$ it is not always clear, which is the ground-state and which is the meta-stable state. For ${ }^{109 g}$ In there was no literature data found, while for ${ }^{108 m}$ In the recent data of Khandaker et al. are slightly lower than ours above $20 \mathrm{MeV}$ and slightly higher below this energy. For the radioisotope ${ }^{108 g}$ In our data agree or in the lower energy region slightly lower than those of (Khandaker et al., 2014). For ${ }^{115 g} \mathrm{Cd}$ our new data are in acceptable agreement with the recent results of (Khandaker et al., 2014). Our new calculated yield for ${ }^{111 m} \mathrm{Cd}$ is in good agreement with the data of (Khandaker et al., 2014) above 20 $\mathrm{MeV}$ and lower below this energy.

\section{Thin layer activation}

While the cadmium metal is widely used in industry as e.g. alloying element, its application for TLA (Thin Layer Activation) (Ditrói et al., 1997, 2012, 2006) is also discussed. Thin layer activation can be used for measurement of wear, corrosion and erosion of different surfaces. From the list of the produced isotopes 


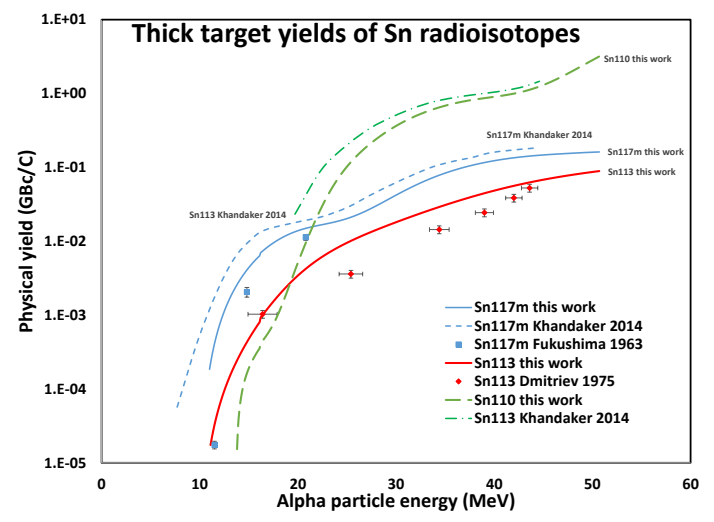

Figure 20: Thick target yields of the produced Sn radioisotopes compared with the previous data from the literature

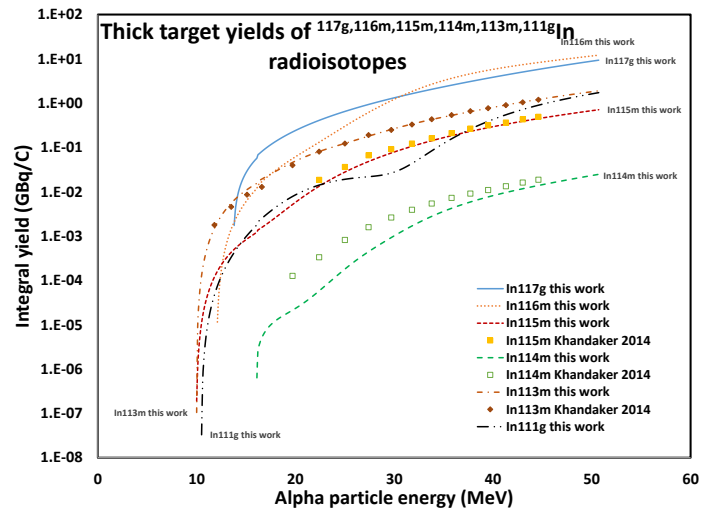

Figure 21: Thick target yields of the produced $117,116 m, 115 m, 114 m, 113 m, 111 g$ In radioisotopes compared with the previous data from the literature

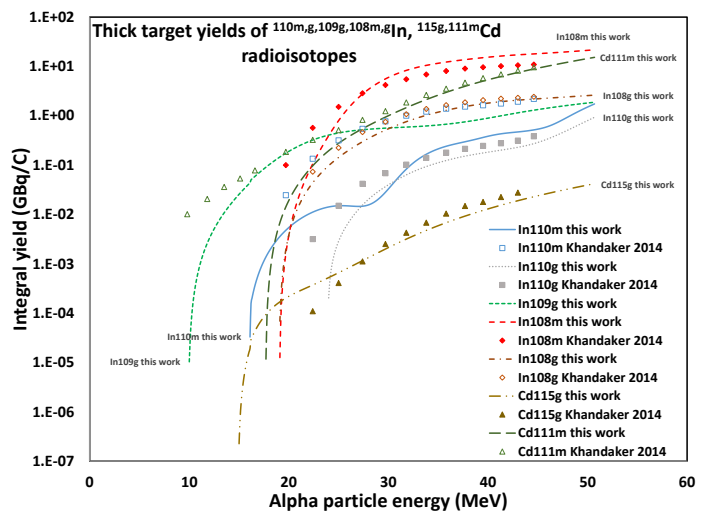

Figure 22: Thick target yields of the produced ${ }^{110 m, g, 109 g, 108 m}$ In and ${ }^{115 g, 111 m} \mathrm{Cd}$ radioisotopes compared with the previous data from the literature

${ }^{113} \mathrm{Sn}$ is the most proper choice for thin layer activation because of its convenient half-life $\left(\mathrm{T}_{1 / 2}=115.09\right.$ d), relatively high production cross section (Fig. 4) and the intense gamma-lines (Table 1). Another advantage is that it has local maxima in cross section, which make possible to produce homogeneous activity distribution until a given depth of the surface. Other good candidates are ${ }^{114 m}$ In and ${ }^{111}$ In, which also have still proper nuclear parameters, but have no maximum in the excitation function, which means that only linear activity distribution can be produced. In Fig. 23 the TLA activity distribution curves for ${ }^{113} \mathrm{Sn}$ are seen, both with 42.1 $\mathrm{MeV}$ bombarding energy and 1 hour $2 \mu \mathrm{A}$ irradiation parameters. In the first case $\left(15^{\circ}\right.$ irradiation angle) the homogeneity limit (within $1 \%$ ) is $10.1 \mu \mathrm{m}$ with $80 \mu \mathrm{m}$ total penetration depth, while for perpendicular irradiation these values are 39 and $300 \mu \mathrm{m}$, respectively considering $100 \%$ cadmium in the investigated specimen. It demonstrates that the activity distribution can be tuned in wide depth range according to the requirements of the actual wear measurement task. To demonstrate the linear case, the activity distribution of ${ }^{114 m}$ In is also shown in Fig. 23. The results are calculated with the same irradiation time and beam intensity but with $40 \mathrm{MeV}$ bombarding energy. The linearity limit at the first case $\left(15^{\circ}\right.$ irradiation angle) is $12.2 \mu \mathrm{m}$ by $60 \mu \mathrm{m}$ total penetration depth and by the perpendicular irradiation these values are $47.2 \mu \mathrm{m}$ and $250 \mu \mathrm{m}$, respectively. While by the homogeneous activity distribution the bombarding energy is fixed to an optimum value, by the linear distribution not only the irradiation angle but also the bombarding energy can be varied in order to achieve the desired ac- 


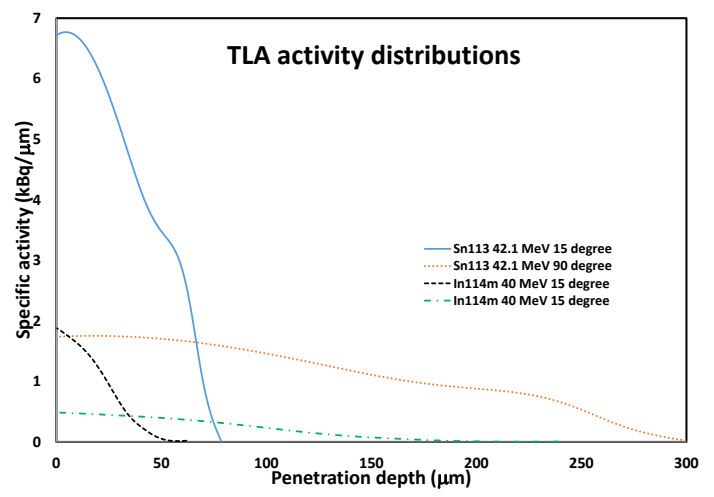

Figure 23: TLA activity distributions calculated for ${ }^{113} \mathrm{Sn}$ and ${ }^{114 m} \mathrm{In}$ with 1 hour $2 \mu \mathrm{A}$ irradiations (activity data taken at the End of Bombardment)

tivity distribution for the particular task.

\section{Summary and conclusions}

In this study we measured alpha particle induced cross sections for the ${ }^{117 m} \mathrm{Sn},{ }^{113} \mathrm{Sn},{ }^{110} \mathrm{Sn},{ }^{117 m, g} \mathrm{In}$, ${ }^{116 m} \mathrm{In},{ }^{115 m} \mathrm{In},{ }^{114 m} \mathrm{In},{ }^{113 m} \mathrm{In},{ }^{111} \mathrm{In},{ }^{110 m, g} \mathrm{In},{ }^{109 m} \mathrm{In}$, ${ }^{108 m} \mathrm{In},{ }^{115 g} \mathrm{Cd}$ and ${ }^{111 m} \mathrm{Cd}$ radioisotopes by irradiating natural cadmium targets. The new data were compared with the previous data from the literature and with the results of the theoretical nuclear reaction model code calculations with TALYS 1.8 (TENDL-2015) and EMPIRE 3.2 (Malta). In the case of some radioisotopes we extended the energy range of the available data $\left({ }^{117} \mathrm{I} \mathrm{In}\right.$, ${ }^{116 m} \mathrm{In},{ }^{113 m} \mathrm{In},{ }^{110 m} \mathrm{In},{ }^{108 m} \mathrm{In}$, and $\left.{ }^{111 m} \mathrm{Cd}\right)$, in other cases tried to dissolve the discrepancy between the existing data sets $\left({ }^{117 m} \mathrm{Sn},{ }^{113} \mathrm{Sn},{ }^{111} \mathrm{In},{ }^{110 m} \mathrm{In},{ }^{109 g} \mathrm{In}\right.$, and $\left.{ }^{115 g} \mathrm{Cd}\right)$, or we have confirmed the existing data $\left({ }^{110} \mathrm{Sn}\right.$, ${ }^{117 g}$ In, ${ }^{116 m}$ In, ${ }^{115 m}$ In, ${ }^{114 m}$ In, ${ }^{113 m}$ In, ${ }^{110 g}$ In, ${ }^{108 g}$ In, and ${ }^{111}{ }^{m} \mathrm{Cd}$ ). These tasks were successfully completed in most cases. The comparison with the model code results shows that their approach by alpha induced reactions, which are more favorable in excitation of high spin isomeric state is not satisfactory. In most cases the data from the TENDL-2015 on-line library (Koning et al., 2015 b) gave better approximation (e.g. ${ }^{113} \mathrm{Sn},{ }^{110} \mathrm{Sn}$, etc.), but there were cases where EMPIRE 3.2 delivered better approximation (e. g. ${ }^{108 g}$ In), but in one case both failed completely $\left({ }^{111 m} \mathrm{Cd}\right)$. For comparison the thick target physical yields were calculated from the experimental excitation functions and compared with the available literature data. The data in Figs. 20-22 show an acceptable agreement in most cases. A serious disagreement was seen only in the case on ${ }^{110 m} \mathrm{In}$, where also a possible explanation is given. The applicability of some produced radioisotopes for wear measurement by using thin layer activation is also demonstrated.

\section{Acknowledgements}

This work was performed at the RI Beam Factory operated by the RIKEN Nishina Center and CNS, University of Tokyo. This work was carried out in the frame of the standing HAS-JSPS (Hungary Japan) bilateral exchange agreement. The authors acknowledge the support of the respective institutions in providing technical support and use of experimental facilities. (Contract No.: NKM-89/2014).

\section{References}

Adam-Rebeles, R., Hermanne, A., Van den Winkel, P., Tárkányi, F., Takács, S., Daraban, L., 2008. Alpha induced reactions on (114)cd and (116)cd: An experimental study of excitation functions. Nuclear Instruments \& Methods in Physics Research Section B-Beam Interactions with Materials and Atoms 266 (21), 4731-4737.

Andreyev, O. I., Vakhetov, F. Z., Kuznetsov, R. A., Tselishev, I. V., 1999. 113sn and $117 \mathrm{msn}$ production technology.

Baum, R. P. E., 2014. Therapeutic Nuclear Medicine. Springer, Berlin, Heidelberg.

Capote, R., Herman, M., Oblozinsky, P., Young, P. G., Goriely, S., Belgya, T., Ignatyuk, A. V., Koning, A. J., Hilaire, S., Plujko, V. A., Avrigeanu, M., Bersillon, O., Chadwick, M. B., Fukahori, T., Ge, Z., Han, Y., Kailas, S., Kopecky, J., Maslov, V. M., Reffo, G., Sin, M., Soukhovitskii, E. S., Talou, P., 2009. Reference input parameter library (ripl-3). Nuclear Data Sheets 110 (12), 3107-3214.

Ditrói, F., Fehsenfeld, P., Khanna, A. S., Konstantinov, I., Majhunka, I., Racolta, P. M., Sauvage, T., Thereska, J., 1997. The thin layer activation method and its applications in industry. Tech. rep.

Ditrói, F., Takács, S., Haba, H., Komori, Y., Aikawa, M., Sz" ucs, Z., Saito, M., 2016. Excitation function of the alpha particle induced nuclear reactions on enriched $116 \mathrm{~cd}$, production of the $117 \mathrm{msn}$ theranostic isotope. Nuclear Instruments \& Methods in Physics Research B 385, 1-8.

Ditrói, F., Takács, S., Tárkányi, F., Corniani, E., Smith, R. W., Jech, M., Wopelka, T., 2012. Sub-micron wear measurement using activities under the free handling limit. Journal of Radioanalytical and Nuclear Chemistry 292 (3), 1147-1152.

Ditrói, F., Takács, S., Tárkányi, F., Reichel, M., Scherge, M., Gerve, A., 2006. Thin layer activation of large areas for wear study. Wear 261 (11-12), 1397-1400.

Dmitriev, P. P., Panarin, M. V., Molin, G. A., Dmitrieva, Z. P., 1975. Yields of sn-113 and sn- $117 \mathrm{~m}$ in nuclear-reactions with protons, deuterons, and alpha-particles. Soviet Atomic Energy 39 (2), 734735.

Duchemin, C., Essayan, M., Guertin, A., Haddad, F., Michel, N., M 辿 tivier, V., 2016. How to produce high specific activity tin-117 $\mathrm{m}$ using alpha particle beam. Applied Radiation and Isotopes 115, $113-124$. 
Ermolaev, S. V., Zhuikov, B. L., Kokhanyuk, V. M., Abramov, A. A., Togaeva, N. R., Khamianov, S. V., Srivastava, S. C., 2009. Production of no-carrier-added sn- $117 \mathrm{~m}$ from proton irradiated antimony. Journal of Radioanalytical and Nuclear Chemistry 280 (2), 319324.

Fukushima, S., Hayashi, S., Kume, S., Okamura, H., Otozai, K., Sakamoto, K., Tsujini, R., 1963. The production of high specific activities of tin. Bull. Chem. Soc. Jp. 36, 1225.

Herman, M., Capote, R., Carlson, B. V., Oblozinsky, P., Sin, M., Trkov, A., Wienke, H., Zerkin, V., 2007. Empire: Nuclear reaction model code system for data evaluation. Nuclear Data Sheets 108 (12), 2655-2715.

Herman, M., Capote, R., Sin, M., Trkov, A., Carlson, B., Oblozinsky, P., Mattoon, C., Wienke, H., Hoblit, S., Cho, Y.-S., Plujko, V., Zerkin, V., 2012. Nuclear reaction model code empire-3.2 (malta).

Hermanne, A., Daraban, L., Rebeles, R. A., Ignatyuk, A., Tárkányi, F., Takács, S., 2010. Alpha induced reactions on natcd up to 38.5 mev: Experimental and theoretical studies of the excitation functions. Nuclear Instruments \& Methods in Physics Research Section B 268 (9), 1376-1391.

International-Cadmium-Association, 2016. Cadmium, working towards a sutainable future, www.cadmium.org.

Khandaker, M. U., Kim, K., Lee, M., Kim, G., 2014. Investigation of activation cross-sections of alpha-induced nuclear reactions on natural cadmium. Nuclear Instruments \& Methods in Physics Research Section B-Beam Interactions with Materials and Atoms 333, 80-91.

Knapp, F. F., J., Callahan, A. P., Ambrose, K. R., Ferren, L. A., Butler, T. A., Coffey, J. L., 1983. Potential tissue-imaging agents: 23-(trimethyl [117msn]stannyl)-24-nor-5 alpha-cholan-3 beta-ol. J Med Chem 26 (10), 1535-7.

Koning, A., Hilaire, S., Duijvestijn, M., 2015a. What is talys?

Koning, A. J., Hilaire, S., Duijvestijn, M. C., 2007. Talys-1.0.

Koning, A. J., Rochman, D., 2013. Talys-based evaluated nuclear data library.

Koning, A. J., Rochman, D., Kopecky, J., Sublet, J. C., Bauge, E., Hilaire, S., Romain, P., Morillon, B., Duarte, H., van der Marck, S., Pomp, S., Sjostrand, H., Forrest, R., Henriksson, H., Cabellos, O., S., G., Leppanen, J., Leeb, H., Plompen, A., Mills, R., 2015 b. Tendl-2015: Talys-based evaluated nuclear data library,

Maslov, O. D., Starodub, G. Y., Vostokin, G. K., Gustova, M. V., Dmitriev, S. N., Shvetsov, V. N., Szücs, Z., Jansen, D., Zeevaart, J. R., 2011. Production of sn-117m with high specific activity by cyclotron. Applied Radiation and Isotopes 69 (7), 965-968.

Mausner, L. F., Mirzadeh, S., Ward, T. E., 1985. Nuclear data for production of $117 \mathrm{msn}$ for biomedical application. In: International Conference on Nuclear Data for Basic and Applied Science. pp. 733-737.

NuDat, 2014. Nudat2 database (2.6).

Pritychenko, B., Sonzogni, A., 2003. Q-value calculator

Qaim, S. M., 2012. The present and future of medical radionuclide production. Radiochimica Acta 100 (8-9), 635-651.

Qaim, S. M., 2015. Nuclear data for medical radionuclides. Journal of Radioanalytical and Nuclear Chemistry 305 (1), 233-245.

Qaim, S. M., Dohler, H., 1984. Production of carrier-free sn-117m. International Journal of Applied Radiation and Isotopes 35 (7), 645650.

Simon, J., Rogers, J. A., Frank, K., Mueller, D. W., Stevenson, N. R., 2013. Sn-117m labeled annexin for vulnerable plaque. Abstracts of Papers of the American Chemical Society 245.

Srivastava, S. C., Toporov, Y. G., Karelin, E. A., Vakhetov, F. Z., Andreev, O. I., Tshelishev, I. V., Popov, Y. S., 2004. Optimization of the reactor production of high-specific activity tin-117m for bone pain treatment and bone cancer therapy. European Journal of $\mathrm{Nu}-$ clear Medicine and Molecular Imaging 31, S481-S481.
Stevenson, N. R., St George, G., Simon, J., Srivastava, S. C., Mueller, D. W., Gonzales, G. R., Rogers, J. A., Frank, R. K., Horn, I. M., 2015. Methods of producing high specific activity sn-117m with commercial cyclotrons. Journal of Radioanalytical and Nuclear Chemistry 305 (1), 99-108.

Tárkányi, F., Takács, S., Gul, K., Hermanne, A., Mustafa, M. G., Nortier, M., Oblozinsky, P., Qaim, S. M., Scholten, B., Shubin, Y. N., Youxiang, Z., 2001. Beam monitor reactions (chapter 4). charged particle cross-section database for medical radioisotope production: diagnostic radioisotopes and monitor reactions. Tech. rep., IAEA.

Watanabe, T., 2015.

Watanabe, T., Fujimaki, M., Fukunishi, N., Imao, H., Kamigaito, O., Kase, M., Komiyama, M., Sakamoto, N., Suda, K., Wakasugi, M., Yamada, K., 2014. Beam energy and longitudinal beam profile measurement system at ribf. 
Table 1: Nuclear data for the radioisotopes in this experiment (NuDat, 2014; Pritychenko and Sonzogni, 2003)

\begin{tabular}{|c|c|c|c|c|c|c|}
\hline $\begin{array}{l}\text { Isotope } \\
\text { spin } \\
\text { level energy(keV) }\end{array}$ & Half-life & $\begin{array}{l}\text { Decay mode } \\
(\%)\end{array}$ & $\begin{array}{l}\mathbf{E}_{\gamma} \\
(\mathbf{k e V})\end{array}$ & $\begin{array}{l}\mathbf{I}_{\gamma} \\
(\%)\end{array}$ & $\begin{array}{l}\text { Contributing reac- } \\
\text { tions }\end{array}$ & $\begin{array}{l}\text { Threshold } \\
\text { (MeV) }\end{array}$ \\
\hline${ }^{117 m_{S n}}$ & $14 \mathrm{~d}$ & IT 100 & 156.02 & 2.113 & $716^{6 d}(\alpha, 3 \mathrm{n})$ & 21.11 \\
\hline $11 / 2^{-}$ & & & 158.56 & 86.4 & ${ }^{114} \mathrm{Cd}(\alpha, \mathrm{n})$ & 5.76 \\
\hline 314.58 & & & & & 717 In decay & \\
\hline${ }^{113} \mathrm{Sn}$ & $115.09 \mathrm{~d}$ & $\varepsilon 100$ & 391.70 & 64.97 & ${ }^{110} \mathrm{Cd}(\alpha, \mathrm{n})$ & 7.95 \\
\hline \multirow[t]{4}{*}{$1 / 2^{+}$} & & & & & $71 \mathrm{Cd}_{\mathrm{Cd}(\alpha, 2 \mathrm{n})}$ & 15.17 \\
\hline & & & & & ${ }^{112} \mathrm{Cd}(\alpha, 3 \mathrm{n})$ & 24.90 \\
\hline & & & & & ${ }^{113} \mathrm{Cd}(\alpha, 4 \mathrm{n})$ & 31.66 \\
\hline & & & & & ${ }^{114} \mathrm{Cd}(\alpha, 5 \mathrm{n})$ & 41.01 \\
\hline${ }^{110} \mathrm{Sn}$ & $4.11 \mathrm{~h}$ & $\varepsilon 100$ & 280.46 & 97 & ${ }^{108} \mathrm{Cd}(\alpha, 2 \mathrm{n})$ & 17.76 \\
\hline \multirow[t]{2}{*}{$0^{+}$} & & & & & $110{ }^{\circ} \mathrm{Cd}(\alpha, 4 \mathrm{n})$ & 35.69 \\
\hline & & & & & $111 \mathrm{Cd}(\alpha, 5 \mathrm{n})$ & 42.83 \\
\hline $117 m_{\text {In }}$ & $116.2 \mathrm{~min}$ & IT 47.1 & 315.30 & 19.1 & $116^{6 d}(\alpha, 2 n p)$ & 21.81 \\
\hline $1 / 2^{-}$ & & $\beta^{-} 52.9$ & & & $114 \mathrm{Cd}(\alpha, \mathrm{p})$ & 6.46 \\
\hline 315.30 & & & & & ${ }^{117} \mathrm{Cd}$ decay & \\
\hline $717 g_{\operatorname{In}}$ & $43.2 \mathrm{~min}$ & $\beta^{-} 100$ & 158.6 & 87 & $716_{\mathrm{Cd}}(\alpha, 2 \mathrm{np})$ & 21.49 \\
\hline \multirow[t]{2}{*}{$9 / 2^{+}$} & & & 552.9 & 100 & ${ }^{114} \mathrm{Cd}(\alpha, \mathrm{p})$ & 6.14 \\
\hline & & & & & 717 In decay & \\
\hline $116 m_{\text {In }}$ & $54.29 \mathrm{~min}$ & $\beta^{-} 100$ & 1097.28 & 58.5 & ${ }^{116} \mathrm{Cd}(\alpha, 3 \mathrm{np})$ & 21.49 \\
\hline $5^{+}$ & & & 1293.56 & 84.8 & $114_{\mathrm{Cd}}(\alpha, \mathrm{np})$ & 15.34 \\
\hline 127.28 & & & & & ${ }^{113} \mathrm{Cd}(\alpha, \mathrm{p})$ & 5.99 \\
\hline $115 m_{\operatorname{In}}$ & $4.486 \mathrm{~h}$ & IT 95 & 336.24 & 45.8 & $716 \mathrm{Cd}(\alpha, 4 \mathrm{np})$ & 37.92 \\
\hline $1 / 2^{-}$ & & $\beta^{-} 5$ & & & ${ }^{114} \mathrm{Cd}(\alpha, 2 \mathrm{np})$ & 22.58 \\
\hline \multirow[t]{3}{*}{336.24} & & & & & ${ }^{113} \mathrm{Cd}(\alpha, \mathrm{np})$ & 13.22 \\
\hline & & & & & ${ }^{112} \mathrm{Cd}(\alpha, \mathrm{p})$ & 6.45 \\
\hline & & & & & ${ }^{115} \mathrm{Cd}$ decay & \\
\hline${ }^{114 m}$ In & $49.51 \mathrm{~d}$ & IT 100 & 190.27 & 15.56 & ${ }^{711} \mathrm{Cd}(\alpha, \mathrm{p})$ & 5.94 \\
\hline $5^{+}$ & & & & & ${ }^{112} \mathrm{Cd}(\alpha, \mathrm{np})$ & 15.67 \\
\hline \multirow[t]{3}{*}{190.27} & & & & & ${ }^{113} \mathrm{Cd}(\alpha, 2 \mathrm{np})$ & 22.43 \\
\hline & & & & & ${ }^{114} \mathrm{Cd}(\alpha, 3 \mathrm{np})$ & 31.79 \\
\hline & & & & & ${ }^{116} \mathrm{Cd}(\alpha, 5 \mathrm{np})$ & 47.12 \\
\hline $113 m_{\operatorname{In}}$ & $\begin{array}{l}99.476 \\
\min \end{array}$ & IT 100 & 391.70 & 64.94 & ${ }^{110} \mathrm{Cd}(\alpha, \mathrm{p})$ & 6.45 \\
\hline $1 / 2^{+}$ & & & & & ${ }^{111} \mathrm{Cd}(\alpha, \mathrm{np})$ & 13.68 \\
\hline \multirow{3}{*}{391.69} & & & & & ${ }^{112} \mathrm{Cd}(\alpha, 2 \mathrm{np})$ & 23.40 \\
\hline & & & & & ${ }^{113} \mathrm{Cd}(\alpha, 3 \mathrm{np})$ & 30.17 \\
\hline & & & & & $714^{\mathrm{Cd}(\alpha, 4 \mathrm{np})}$ & 39.52 \\
\hline${ }^{111} \mathrm{In}$ & $2.8047 \mathrm{~d}$ & $\varepsilon 100$ & 171.28 & 90.7 & ${ }^{108} \mathrm{Cd}(\alpha, \mathrm{p})$ & 5.94 \\
\hline \multirow{4}{*}{$9 / 2^{+}$} & & & 245.35 & 94.1 & $1100 \mathrm{Cd}(\alpha, 2 \mathrm{np})$ & 23.80 \\
\hline & & & & & ${ }^{111} \mathrm{Cd}(\alpha, 3 \mathrm{np})$ & 31.02 \\
\hline & & & & & $112 \mathrm{Cd}(\alpha, 4 \mathrm{np})$ & 40.74 \\
\hline & & & & & ${ }^{113} \mathrm{Cd}(\alpha, 5 \mathrm{np})$ & 47.50 \\
\hline $71 \log _{\mathrm{In}}$ & $4.92 \mathrm{~h}$ & $\varepsilon 100$ & 657.75 & 98 & ${ }^{108} \mathrm{Cd}(\alpha, \mathrm{np})$ & 16.30 \\
\hline \multirow[t]{3}{*}{$7^{+}$} & & & 884.68 & 93 & $1100 \mathrm{Cd}(?, 3 \mathrm{np})$ & 34.16 \\
\hline & & & & & $711 \mathrm{Cd}(\alpha, 4 \mathrm{np})$ & 41.37 \\
\hline & & & & & ${ }^{1112} \mathrm{Cd}(\alpha, 5 \mathrm{np})$ & 51.09 \\
\hline $110 m_{\mathrm{In}}$ & $69.1 \mathrm{~min}$ & $\varepsilon 100$ & 657.75 & 97.74 & $108 \mathrm{Cd}(\alpha, \mathrm{np})$ & 16.36 \\
\hline $2^{+}$ & & & & & $1100 \mathrm{Cd}(\alpha, 3 \mathrm{np})$ & 34.22 \\
\hline \multirow[t]{2}{*}{62.08} & & & & & ${ }^{111} \mathrm{Cd}(\alpha, 4 \mathrm{np})$ & 41.43 \\
\hline & & & & & ${ }^{112} \mathrm{Cd}(\alpha, 5 \mathrm{np})$ & 51.15 \\
\hline${ }^{109 g}$ In & $4.167 \mathrm{~h}$ & $\varepsilon 100$ & 203.5 & 73.5 & ${ }^{106} \mathrm{Cd}(\alpha, \mathrm{p})$ & 10.53 \\
\hline $9 / 2^{+}$ & & & & & ${ }^{108} \mathrm{Cd}(\alpha, 2 \mathrm{np})$ & 24.65 \\
\hline & & & & & $710_{\mathrm{Cd}(\alpha, 4 \mathrm{np})}$ & 42.50 \\
\hline & & & & & $111 \mathrm{Cd}(\alpha, 5 \mathrm{np})$ & 49.72 \\
\hline $108 m_{\text {In }}$ & $39.6 \mathrm{~min}$ & $\varepsilon 100$ & 632.9 & 76.4 & ${ }^{106} \mathrm{Cd}(\alpha, \mathrm{np})$ & 16.58 \\
\hline $2^{+}$ & & & & & ${ }^{108} \mathrm{Cd}(\alpha, 3 \mathrm{np})$ & 35.51 \\
\hline 29.76 & & & & & & \\
\hline $115 g_{\mathrm{Cd}}$ & $53.46 \mathrm{~h}$ & $\beta^{-} 100$ & 527.90 & 27.5 & ${ }^{116} \mathrm{Cd}(\alpha, 3 \mathrm{n} 2 \mathrm{p})$ & 38.45 \\
\hline $1 / 2^{+}$ & & & & & ${ }^{116} \mathrm{Cd}(\alpha, \mathrm{n} \alpha)$ & 9.18 \\
\hline & & & & & ${ }^{114} \mathrm{Cd}(\alpha, \mathrm{n} 2 \mathrm{p})$ & 22.93 \\
\hline & & & & & ${ }^{113} \mathrm{Cd}(\alpha, 2 \mathrm{p})$ & 13.58 \\
\hline & & & & & $115 \mathrm{Ag}$ decay & \\
\hline${ }^{115 m} \mathrm{Cd}$ & $44.56 \mathrm{~d}$ & $\beta^{-} 100$ & 933.84 & 2 & ${ }^{116} \mathrm{Cd}(\alpha, 3 \mathrm{n} 2 \mathrm{p})$ & 38.63 \\
\hline $11 / 2^{-}$ & & & & & ${ }^{116} \mathrm{Cd}(\alpha, \mathrm{n} \alpha)$ & 9.36 \\
\hline 181.05 & & & & & $114 \mathrm{Cd}(\alpha, \mathrm{n} 2 \mathrm{p})$ & 23.11 \\
\hline & & & & & ${ }^{113} \mathrm{Cd}(\alpha, 2 \mathrm{p})$ & 13.76 \\
\hline & & & & & $115 \mathrm{Ag}$ decay & \\
\hline $111 m_{\mathrm{Cd}}$ & $48.5 \mathrm{~min}$ & IT 100 & 150.83 & 19.1 & $1100 \mathrm{Cd}(\alpha, \mathrm{n} 2 \mathrm{p})$ & 22.49 \\
\hline $11 / 2^{-}$ & & & & & ${ }^{111} \mathrm{Cd}(\alpha, 2 \mathrm{n} 2 \mathrm{p})$ & 29.71 \\
\hline 396.22 & & & & & ${ }^{112} \mathrm{Cd}(\alpha, 3 \mathrm{n} 2 \mathrm{p})$ & 39.43 \\
\hline & & & & & ${ }^{112} \mathrm{Cd}(\alpha, \mathrm{n} \alpha)$ & 10.13 \\
\hline & & & & & ${ }^{113} \mathrm{Cd}(\alpha, 4 \mathrm{n} 2 \mathrm{p})$ & 46.19 \\
\hline & & & & & ${ }^{113} \mathrm{Cd}(\alpha, 2 \mathrm{n} \alpha)$ & 16.89 \\
\hline & & & & & $114 \mathrm{Cd}(\alpha, 3 \mathrm{n} \alpha)$ & 26.25 \\
\hline & & & & & ${ }^{116} \mathrm{Cd}(\alpha, 5 \mathrm{n} \alpha)$ & 41.69 \\
\hline
\end{tabular}


Table 2: Measured cross sections of the ${ }^{n a t} \mathrm{Cd}(\alpha, \mathrm{x})^{117 m, 113,110} \mathrm{Sn},{ }^{117 m, 117 g, 116 m, 115 m, 114 m}$ In nuclear reactions

\begin{tabular}{|c|c|c|c|c|c|c|c|c|c|c|c|c|c|c|c|c|c|}
\hline \multicolumn{2}{|c|}{ Alpha Energy } & \multicolumn{2}{|c|}{${ }^{117 m} \mathbf{S n}$} & \multicolumn{2}{|c|}{${ }^{113} \mathbf{S n}$} & \multicolumn{2}{|c|}{${ }^{110} \mathbf{S n}$} & \multicolumn{2}{|c|}{${ }^{117 m} \mathbf{I n}$} & \multicolumn{2}{|c|}{${ }^{1177} g_{\text {In }}$} & \multicolumn{2}{|c|}{${ }^{116 m} \mathbf{I n}$} & \multicolumn{2}{|c|}{$115 m \mathbf{I n}$} & \multicolumn{2}{|c|}{${ }^{114 m} \mathbf{I n}$} \\
\hline $\mathbf{E}$ & $\Delta \mathbf{E}$ & $\sigma$ & $\Delta \sigma$ & $\sigma$ & $\Delta \sigma$ & $\sigma$ & $\Delta \sigma$ & $\sigma$ & $\Delta \sigma$ & $\sigma$ & $\Delta \sigma$ & $\sigma$ & $\Delta \sigma$ & $\sigma$ & $\Delta \sigma$ & $\sigma$ & $\Delta \sigma$ \\
\hline \multicolumn{2}{|c|}{ MeV } & \multicolumn{16}{|c|}{$\mathrm{mb}$} \\
\hline 50.7 & 0.3 & 14.9 & 1.6 & 235.4 & 25.5 & 53.8 & 5.8 & & & 11.8 & 1.4 & 15.9 & 1.8 & 4.7 & 0.7 & 64.1 & 7.1 \\
\hline 49.7 & 0.3 & 16.9 & 1.9 & 238.6 & 26.3 & 47.8 & 5.2 & & & 12.0 & 1.4 & 14.9 & 1.8 & & & 57.8 & 10.8 \\
\hline 48.1 & 0.4 & 24.0 & 2.6 & 244.6 & 28.1 & 36.0 & 3.9 & & & 12.0 & 1.4 & 15.0 & 1.8 & 5.1 & 0.7 & 62.4 & 9.5 \\
\hline 47.0 & 0.4 & 20.5 & 2.3 & 246.6 & 27.2 & 26.9 & 2.9 & & & 9.9 & 1.1 & 13.7 & 1.6 & 4.0 & 0.6 & 41.1 & 7.0 \\
\hline 45.4 & 0.4 & 30.5 & 3.3 & 278.5 & 30.6 & 20.6 & 2.2 & & & 12.1 & 1.4 & 13.6 & 1.7 & 5.8 & 0.8 & 55.6 & 10.1 \\
\hline 44.3 & 0.4 & 29.5 & 3.2 & 285.5 & 31.3 & 12.6 & 1.4 & & & 9.0 & 1.0 & 12.4 & 1.4 & 4.3 & 0.6 & 47.2 & 8.9 \\
\hline 42.6 & 0.5 & 47.8 & 5.2 & 318.5 & 34.8 & 8.5 & 0.9 & 0.78 & 0.23 & 9.5 & 1.1 & 13.3 & 1.5 & 4.2 & 0.5 & 40.4 & 8.8 \\
\hline 41.4 & 0.5 & 50.2 & 5.4 & 315.7 & 34.5 & 5.7 & 0.6 & & & 8.7 & 1.0 & 13.8 & 1.5 & 4.5 & 0.6 & 30.4 & 6.0 \\
\hline 39.6 & 0.6 & 67.5 & 7.3 & 305.8 & 33.4 & 4.5 & 0.5 & & & 7.4 & 0.8 & 13.5 & 1.5 & 3.2 & 0.5 & 45.6 & 7.1 \\
\hline 38.4 & 0.6 & 72.4 & 7.8 & 303.0 & 33.1 & 4.4 & 0.5 & 0.43 & 0.19 & 6.8 & 0.7 & 13.2 & 1.5 & 3.4 & 0.5 & 30.2 & 5.6 \\
\hline 36.5 & 0.6 & 87.4 & 9.5 & 278.6 & 30.4 & 6.4 & 0.7 & & & 5.7 & 0.6 & 14.3 & 1.6 & 3.6 & 0.5 & 30.6 & 5.9 \\
\hline 35.2 & 0.7 & 89.5 & 9.7 & 266.5 & 29.1 & 7.2 & 0.8 & 0.37 & 0.14 & 4.4 & 0.5 & 13.4 & 1.5 & 3.0 & 0.4 & 33.1 & 6.1 \\
\hline 33.2 & 0.7 & 97.7 & 10.6 & 242.8 & 26.6 & 8.6 & 0.9 & 0.41 & 0.36 & 4.5 & 0.5 & 13.1 & 1.4 & 3.3 & 0.5 & 24.1 & 4.9 \\
\hline 31.8 & 0.7 & 91.3 & 9.9 & 224.9 & 24.6 & 9.3 & 1.0 & 0.79 & 0.35 & 4.7 & 0.7 & 12.9 & 1.6 & 2.7 & 0.4 & 18.3 & 4.0 \\
\hline 29.6 & 0.8 & 80.6 & 8.7 & 191.0 & 21.0 & 9.3 & 1.0 & & & 3.6 & 0.6 & 8.6 & 1.1 & 2.2 & 0.3 & 10.1 & 3.0 \\
\hline 28.0 & 0.8 & 57.6 & 6.2 & 164.1 & 18.1 & 8.3 & 0.9 & & & 4.4 & 0.7 & 6.0 & 0.9 & 1.7 & 0.3 & 6.3 & 2.5 \\
\hline 25.7 & 0.9 & 32.3 & 3.5 & 150.7 & 16.6 & 6.6 & 0.7 & & & 4.4 & 0.7 & 4.0 & 0.6 & 1.3 & 0.2 & 5.6 & 2.3 \\
\hline 24.0 & $\begin{array}{l}0.9 \\
\end{array}$ & 18.8 & 2.0 & 147.0 & $\begin{array}{l}16.2 \\
\end{array}$ & 5.3 & 0.6 & 0.04 & 0.22 & 2.5 & $\begin{array}{l}0.3 \\
\end{array}$ & 2.5 & 0.3 & 1.1 & 0.1 & 2.1 & 1.6 \\
\hline 21.3 & 1.0 & 16.1 & 1.7 & 147.3 & 16.1 & 1.7 & 0.2 & & & 2.9 & 0.5 & 1.1 & 0.3 & 0.7 & 0.1 & & \\
\hline 19.3 & 1.0 & 26.6 & 2.9 & 123.9 & 13.6 & 0.443 & 0.064 & & & 1.7 & 0.4 & 0.7 & 0.2 & 0.3 & 0.1 & & \\
\hline 16.1 & 1.1 & 33.2 & 3.6 & 48.0 & 5.2 & 0.036 & 0.015 & & & & & & & 0.1 & 0.0 & 0.4 & 0.2 \\
\hline 13.8 & 1.1 & & & & & 0.037 & 0.005 & & & 0.74 & 0.17 & & & 0.07 & 0.01 & & \\
\hline
\end{tabular}

Table 3: Measured cross sections of the ${ }^{n a t} \mathrm{Cd}(\alpha, \mathrm{X})^{113 m, 110 m, 110 g, 109 g, 108 m, 108 g} \mathrm{In},{ }^{115 m, 111} \mathrm{Cd}$ nuclear reactions

\begin{tabular}{|c|c|c|c|c|c|c|c|c|c|c|c|c|c|c|c|c|c|c|c|}
\hline \multicolumn{2}{|c|}{ Alpha Energy } & \multicolumn{2}{|c|}{${ }^{113 m} \mathbf{I n}$} & \multicolumn{2}{|c|}{$111 g_{\mathbf{I n}}$} & \multicolumn{2}{|c|}{${ }^{110 m} \mathbf{I n}$} & \multicolumn{2}{|c|}{$\operatorname{lnog}_{\text {In }}$} & \multicolumn{2}{|c|}{${ }^{109 g}$ In } & \multicolumn{2}{|c|}{${ }^{108 m \mathbf{I n}}$} & \multicolumn{2}{|c|}{${ }^{108 g} \mathbf{I n}$} & \multicolumn{2}{|c|}{${ }^{115 g_{\mathbf{C d}}}$} & \multicolumn{2}{|c|}{$111 m^{m} \mathbf{C d}$} \\
\hline $\mathbf{E}$ & $\Delta \mathbf{E}$ & $\sigma$ & $\Delta \sigma$ & $\sigma$ & $\Delta \sigma$ & $\sigma$ & $\Delta \sigma$ & $\sigma$ & $\Delta \sigma$ & $\sigma$ & $\Delta \sigma$ & $\sigma$ & $\Delta \sigma$ & $\sigma$ & $\Delta \sigma$ & $\sigma$ & $\Delta \sigma$ & $\sigma$ & $\Delta \sigma$ \\
\hline \multicolumn{2}{|c|}{ MeV } & \multicolumn{18}{|c|}{$\mathrm{mb}$} \\
\hline 50.7 & 0.3 & 4.8 & 0.6 & 242.9 & 26.3 & 9.3 & 1.4 & 24.4 & 2.8 & 8.9 & 1.3 & 11.6 & 1.4 & 1.6 & 0.6 & 4.9 & 0.5 & 22.5 & 3.6 \\
\hline 49.7 & 0.3 & 5.1 & 0.6 & 245.6 & 26.6 & 7.6 & 1.1 & 20.3 & 2.3 & 9.7 & 1.1 & 11.9 & 1.5 & 1.9 & 0.6 & 4.9 & 0.6 & 24.4 & 3.1 \\
\hline 48.1 & 0.4 & 4.8 & 0.6 & 236.6 & 25.6 & 10.4 & 1.3 & 14.1 & 1.6 & 10.3 & 1.2 & 11.8 & 1.4 & 2.6 & 0.6 & 4.4 & 0.5 & 22.1 & 2.5 \\
\hline 47.0 & 0.4 & 4.2 & 0.5 & 216.1 & 23.4 & 6.7 & 1.0 & 9.9 & 1.1 & 10.0 & 1.1 & 8.4 & 1.0 & 1.7 & 0.5 & 3.6 & 0.5 & 19.7 & 2.4 \\
\hline 45.4 & 0.4 & 5.8 & 0.7 & 218.7 & 23.7 & 1.3 & 0.3 & 6.7 & 0.8 & 10.4 & 1.2 & 11.4 & 1.3 & 1.4 & 0.5 & 3.7 & 0.5 & 27.1 & 3.0 \\
\hline 44.3 & 0.4 & 3.7 & 0.4 & 194.0 & 21.0 & 1.2 & 0.2 & 3.8 & 0.5 & 9.8 & 1.1 & 7.1 & 0.8 & 1.5 & 0.4 & 3.3 & 0.4 & 14.9 & 1.8 \\
\hline 42.6 & 0.5 & 4.7 & 0.5 & 206.2 & 22.3 & 0.6 & 0.2 & 2.4 & 0.3 & 11.1 & 1.2 & 10.2 & 1.1 & 1.8 & 0.4 & 3.5 & 0.4 & 17.5 & 1.9 \\
\hline 41.4 & 0.5 & 4.2 & 0.5 & 183.3 & 19.8 & 0.9 & 0.2 & 2.0 & 0.3 & 9.7 & 1.1 & 10.9 & 1.2 & 2.5 & 0.4 & 3.1 & 0.4 & 16.2 & 1.9 \\
\hline 39.6 & 0.6 & 3.7 & 0.4 & 155.8 & 16.9 & 1.5 & 0.2 & 1.9 & 0.2 & 8.1 & 0.9 & 13.6 & 1.5 & 3.2 & 0.5 & 2.5 & 0.3 & 14.6 & 1.6 \\
\hline 38.4 & 0.6 & 3.2 & 0.4 & 136.4 & 14.8 & 1.1 & 0.2 & $\begin{array}{l}1.9 \\
\end{array}$ & 0.2 & 7.0 & 0.8 & 14.3 & 1.6 & 3.6 & 0.5 & 2.3 & 0.3 & 12.9 & 1.4 \\
\hline 36.5 & 0.6 & 2.8 & 0.3 & 104.5 & \begin{tabular}{ll|}
11.3 \\
\end{tabular} & 1.0 & 0.2 & 2.3 & 0.3 & 4.8 & 0.5 & 15.5 & $\begin{array}{l}1.7 \\
\end{array}$ & 3.9 & 0.4 & 2.2 & 0.3 & 16.9 & $\begin{array}{ll}1.8 \\
\end{array}$ \\
\hline 35.2 & $\begin{array}{l}0.7 \\
\end{array}$ & 2.4 & $\begin{array}{l}0.3 \\
\end{array}$ & 82.1 & 8.9 & 1.3 & 0.2 & 2.3 & 0.3 & 3.7 & 0.4 & 17.4 & $\begin{array}{l}1.9 \\
\end{array}$ & 3.8 & 0.5 & $\begin{array}{l}1.8 \\
\end{array}$ & 0.2 & 10.5 & 1.2 \\
\hline 33.2 & 0.7 & 2.2 & 0.3 & 49.9 & 5.4 & 1.6 & 0.5 & 2.4 & 0.3 & 2.3 & 0.3 & 19.6 & 2.1 & 4.3 & 0.6 & 1.5 & 0.2 & 8.9 & 1.0 \\
\hline \begin{tabular}{|l|}
31.8 \\
\end{tabular} & \begin{tabular}{|l|}
0.7 \\
\end{tabular} & 3.0 & $\begin{array}{l}0.4 \\
\end{array}$ & 29.2 & $\begin{array}{l}3.2 \\
\end{array}$ & $\begin{array}{l}1.6 \\
\end{array}$ & $\begin{array}{l}0.5 \\
\end{array}$ & $\begin{array}{l}2.4 \\
\end{array}$ & 0.3 & 1.8 & 0.2 & \begin{tabular}{|l|}
34.6 \\
\end{tabular} & 4.0 & 4.9 & 0.9 & 1.3 & $\begin{array}{l}0.2 \\
\end{array}$ & 8.5 & 1.4 \\
\hline 29.6 & 0.8 & 2.2 & 0.3 & 8.4 & 0.9 & 0.35 & 0.48 & 1.8 & 0.2 & 2.2 & 0.2 & 30.9 & 3.5 & 3.9 & 0.7 & 0.82 & 0.14 & 5.59 & 1.16 \\
\hline 28.0 & 0.8 & 2.1 & 0.3 & 3.0 & 0.3 & & & 1.5 & 0.2 & 2.9 & 0.3 & 31.0 & 3.6 & 3.0 & 0.6 & 0.57 & 0.10 & 4.02 & 0.79 \\
\hline 25.7 & 0.9 & 1.4 & 0.2 & 3.3 & 0.4 & & & 0.8 & 0.1 & 5.3 & 0.6 & 20.8 & 2.6 & 1.8 & 0.4 & 0.30 & 0.07 & 2.27 & 1.25 \\
\hline 24.0 & 0.9 & 1.0 & 0.1 & 5.0 & 0.5 & 0.07 & 0.24 & 0.4 & 0.1 & 8.1 & 0.9 & 7.0 & 0.8 & 1.6 & 0.2 & 0.40 & 0.09 & 2.54 & 0.32 \\
\hline 21.3 & 1.0 & 1.1 & 0.2 & 7.0 & 0.8 & & & & & $\begin{array}{ll}10.7 \\
\end{array}$ & 1.2 & 1.2 & 0.6 & & & 0.07 & 0.05 & 0.51 & 1.01 \\
\hline 19.3 & 1.0 & 0.9 & $\begin{array}{l}0.1 \\
\end{array}$ & $\begin{array}{l}6.6 \\
\end{array}$ & $\begin{array}{l}0.7 \\
\end{array}$ & & & & & 9.1 & 1.0 & & & & & & & & \\
\hline 16.1 & 1.1 & 0.3 & 0.1 & 3.2 & 0.3 & 0.02 & 0.03 & & & 4.2 & 0.5 & & & & & 0.09 & 0.01 & & \\
\hline 13.8 & 1.1 & 0.32 & 0.04 & & & & & & & & & & & & & & & & \\
\hline
\end{tabular}

